ARTICLE

DOI: $10.1038 / \mathrm{s} 41467-017-02367-6$

OPEN

\title{
VGLUT1 functions as a glutamate/proton exchanger with chloride channel activity in hippocampal glutamatergic synapses
}

\author{
Magalie Martineau (D) 1,4, Raul E. Guzman², Christoph Fahlke² \& Jürgen Klingauf 1,3
}

Glutamate is the major excitatory transmitter in the vertebrate nervous system. To maintain synaptic efficacy, recycling synaptic vesicles (SV) are refilled with glutamate by vesicular glutamate transporters (VGLUTs). The dynamics and mechanism of glutamate uptake in intact neurons are still largely unknown. Here, we show by live-cell imaging with $\mathrm{pH}$ - and chloride-sensitive fluorescent probes in cultured hippocampal neurons of wild-type and VGLUT1-deficient mice that in SVS VGLUT functions as a glutamate/proton exchanger associated with a channel-like chloride conductance. After endocytosis most internalized $\mathrm{Cl}^{-}$ is substituted by glutamate in an electrically, and presumably osmotically, neutral manner, and this process is driven by both the $\mathrm{Cl}^{-}$gradient itself and the proton motive force provided by the vacuolar $\mathrm{H}^{+}$-ATPase. Our results shed light on the transport mechanism of VGLUT under physiological conditions and provide a framework for how modulation of glutamate transport via $\mathrm{Cl}^{-}$and $\mathrm{pH}$ can change synaptic strength.

\footnotetext{
${ }^{1}$ Department of Cellular Biophysics, Institute for Medical Physics and Biophysics, University of Muenster, 48149 Muenster, Germany. ${ }^{2}$ Institute of Complex Systems, Zelluläre Biophysik (ICS-4), Forschungszentrum Jülich, 52425 Jülich, Germany. ${ }^{3}$ IZKF Münster and Cluster of Excellence EXC 1003, Cells in Motion (CiM), 48149 Muenster, Germany. ${ }^{4}$ Present address: University of Bordeaux and Centre National de la Recherche Scientifique, Interdisciplinary Institute for Neuroscience, UMR 5297, F-33000 Bordeaux, France. Correspondence and requests for materials should be addressed to

M.M. (email: magalie.martineau@u-bordeaux.fr) or to J.K. (email: klingauf@uni-muenster.de)
} 
$\mathrm{D}$ uring neurotransmission, synaptic vesicles (SV) are retrieved by endocytosis and refilled with neurotransmitters for a new round of exocytosis ${ }^{1,2}$. The filling of SV with glutamate depends on the activity of vesicular glutamate transporters (VGLUTs). Three isoforms of mammalian VGLUTs (VGLUT1-3) have been identified ${ }^{3}$. Loss of VGLUT abolishes glutamatergic neurotransmission leading to severe cognitive malfunctions and lethality ${ }^{4-6}$. While VGLUT is essential for normal synaptic function ${ }^{3}$, the modulation of its activity or expression is implicated in the pathophysiology of several neurological and psychiatric diseases including schizophrenia, ${ }^{7,8}$, Alzheimer's disease ${ }^{9}$, Parkinson's disease ${ }^{10,11}$ and epilepsy ${ }^{12,13}$. When heterologously expressed in Xenopus oocytes, VGLUTs was initially identified as a sodium-dependent inorganic phosphate transporter ${ }^{14}$, which has delayed their discovery as vesicular glutamate transporters for years ${ }^{15,16}$ and precluded direct electrophysiological analysis of the glutamate transport mechanism. Meanwhile mutations of dileucinelike motifs allowed its retention at the cell surface and first electrophysiological data from heterologous expression systems ${ }^{17}$. a

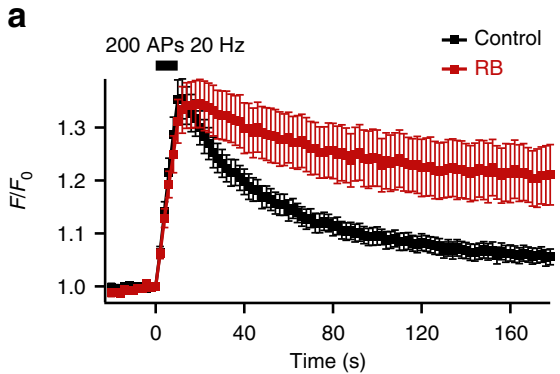

d

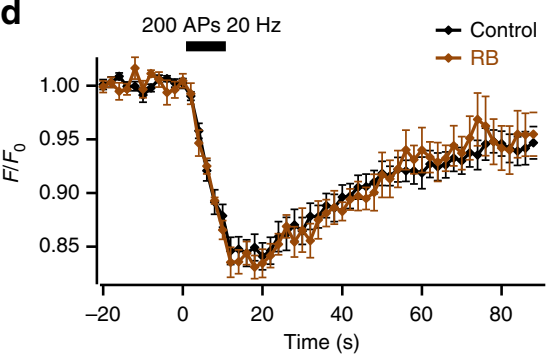

The biochemical characterization of their transport properties in vitro have failed to establish any substantial differences between the three isoforms ${ }^{3}$. Vesicular glutamate transport is driven predominantly by the membrane potential $(\Delta \Psi)$ established by the vacuolar $\mathrm{H}^{+}$-ATPase (V-ATPase) across the vesicular membrane $12,18,19$. One striking feature of VGLUT function is its biphasic dependency on extravesicular chloride ch, $^{3,-}$ 21. In the absence of extravesicular $\mathrm{Cl}^{-}$, glutamate uptake in isolated SVs is very low, whereas low $\mathrm{Cl}^{-}$concentrations $(4 \mathrm{mM})$ strongly activate transport. At higher $\mathrm{Cl}^{-}$concentrations, glutamate transport is gradually inhibited. This complex biphasic dependence might result from an allosteric modulation of VGLUT by $\mathrm{Cl}^{-}$combined with a dissipation of $\Delta \Psi$ resulting from $\mathrm{Cl}^{-}$loading in $\mathrm{SVs}^{3,19}$. Yet, an alternative non-contradictory explanation has been put forward. The expression of VGLUT1 in heterologous systems suggested that VGLUTs might possess an intrinsic $\mathrm{Cl}^{-}$permeability ${ }^{15}$, which recently has been directly confirmed electrophysiologically ${ }^{17}$. VGLUT has also been proposed to contribute to $\mathrm{Cl}^{-}$transport in isolated $\mathrm{SVs}^{22}$. In addition, luminal $\mathrm{Cl}^{-}$concentration influences glutamate transport and storage inside proteoliposomes containing VGLUT $1^{23}$ as

b

Control

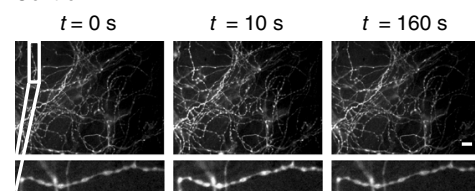

C $_{\mathrm{RB}}$

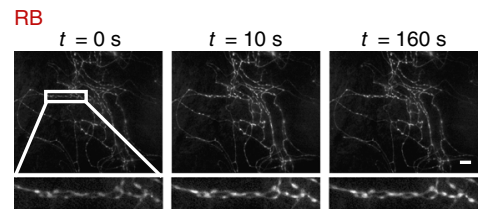

e avGAT-CypHer SpH
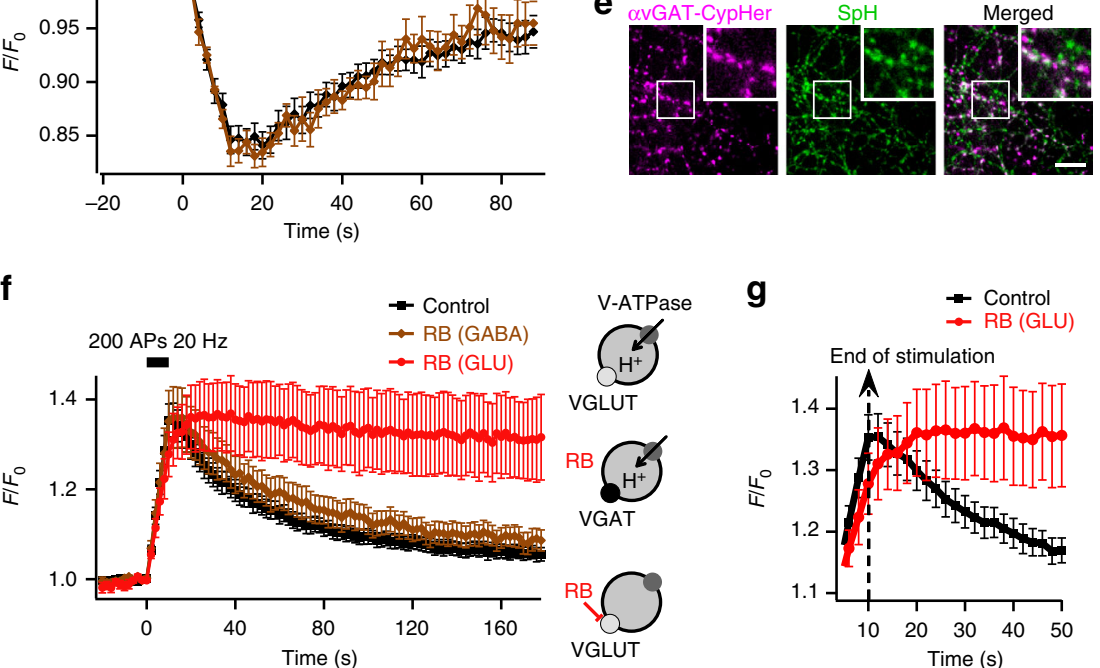

Fig. 1 Inhibition of VGLUT with RB prevents SV re-acidification. a Average SpH fluorescence signals in response to 200 action potentials (APs) at $20 \mathrm{~Hz}$ with or without $\mathrm{RB}(100 \mathrm{nM}, 5 \mathrm{~min}$ ) ( $n=24$ experiments for each condition). b, c Fluorescence images of hippocampal axonal arborisations expressing SpH in control conditions $\mathbf{b}$ or in presence of RB $\mathbf{c}$ at various times after the onset of stimulation. $\mathbf{d}$ Average $\alpha v G A T$-cypHer fluorescence signals in response to stimulation (200 APs $20 \mathrm{~Hz}$ ) with $(n=8)$ or without $(n=12)$ RB. e Fluorescence images of SpH-transfected hippocampal neurons labelled with $\alpha \mathrm{vGAT-}$ cypHer show partial colocalization with $\mathrm{SpH}$ at individual boutons. Scale bars in b-e represent $10 \mu \mathrm{m}$. $\mathbf{f}$ Effect of RB on average SpH fluorescence signals in response to 200 APs at $20 \mathrm{~Hz}$ in GABAergic and glutamatergic boutons ( $n=24$ for control, 11 for GABAergic boutons with RB, 13 for glutamatergic boutons with RB). $\mathbf{g}$ Enlargement of the traces in $\mathbf{f}$ at the climax of stimulation. Note the consistent post-stimulus rise in SpH fluorescence in inhibited glutamatergic boutons due to the sensitivity of inhibited SVs to the activity-dependent transient alkalinisation of the cytosol (Supplementary Fig. 4). The sketches illustrate $\mathrm{H}^{+}$movements. V-ATPase is represented by dark grey-filled circles, VGLUT by light grey-filled circles and VGAT by a black filled circle. Error bars represent s.e.m 
a

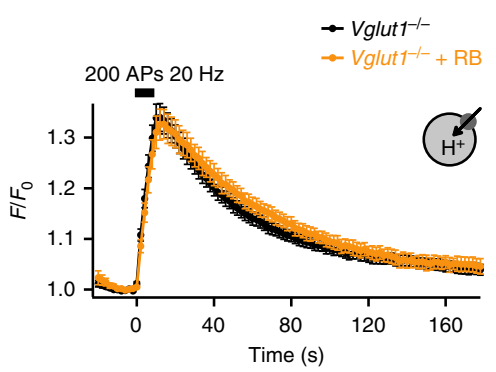

b

$\rightarrow \mathrm{RB} / 129.5 \mathrm{mM} \mathrm{Cl}^{-}$

$\rightarrow \mathrm{RB} / 10.5 \mathrm{mM} \mathrm{Cl}^{-} / 119 \mathrm{mM} \mathrm{MeS}^{-} / 25 \mathrm{mM}$ HEPES

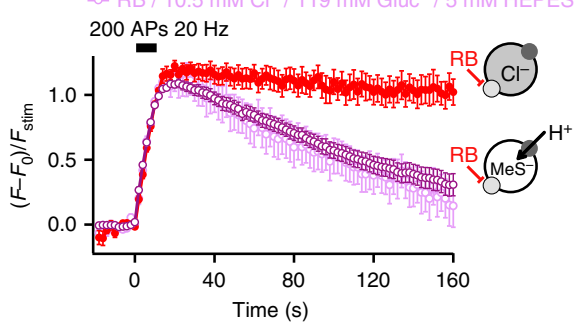

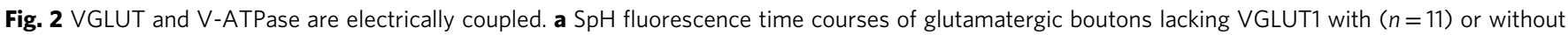
$(n=22)$ RB. b SpH fluorescence time courses upon stimulation (200 APs, $20 \mathrm{~Hz}$ ) with $\mathrm{RB}$ and either normal $\mathrm{Cl}^{-}$concentration (129.5 mM) or a

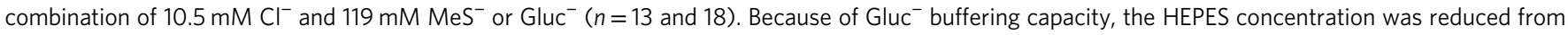

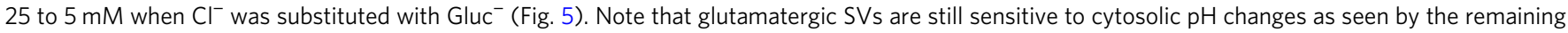
transient post stimulus increase in $\mathrm{SpH}$ fluorescence (Supplementary Fig. 4). The sketches illustrate $\mathrm{H}^{+}$movements. The dark grey and light grey circles symbolize V-ATPase and VGLUT, respectively. Error bars represent s.e.m

well as inside isolated $\mathrm{SVs}^{24}$, reconfirming a modulatory role of the anion suggested earlier ${ }^{12}$. Also protons have been suggested as allosteric modulators of VGLUT activity, since low intravesicular $\mathrm{pH}$ increased the transport rate, but no proton conductivity could be observed in heterologous expression systems ${ }^{17}$ and in isolated $\mathrm{SVs}^{22}$.

In order to study VGLUT properties in conditions that preserve the vesicular environment, we investigated the dynamics of SV acidification and neurotransmitter filling by fast live-cell imaging in situ, i.e. in cultured hippocampal neurons of wild-type and VGLUT1-deficient mice in conjunction with pharmacological interference and ion substitution of the intravesicular solution. Our results demonstrate that glutamate loading into vesicles is fuelled by $\Delta \Psi$ not only produced by V-ATPase activity, but initially mostly by the channel-like chloride efflux from the vesicular lumen. Our data imply that VGLUT is a glutamate/ proton exchanger non-stoichiometrically linked to a channel-like anion $\left(\mathrm{Cl}^{-}\right)$conductance, bestowed by the VGLUT1 protein itself. In addition, we show that glutamate transport is the rate-limiting step during SV acidification, i.e. SV acidification is the result of glutamate loading and not its prerequisite as implied by the allosteric effector model ${ }^{17}$. Therefore, the amount of chloride engulfed in newly endocytosed vesicles governs the reacidification kinetics of glutamatergic SVs. Finally, our data reveal the initial transport rate of VGLUT at hippocampal glutamatergic terminals.

\section{Results}

Rose Bengal blocks re-acidification of newly endocytosed SVs. To monitor the luminal $\mathrm{pH}$ of SV, we expressed the $\mathrm{pH}$-sensitive variant of GFP, pHluorin, coupled to the luminal domain of synaptobrevin 2 (synaptopHluorin, $\mathrm{SpH}$ ) in cultured hippocampal neurons. Electrical stimulation triggered SV fusion with the plasma membrane. Exposure of $\mathrm{SpH}$ to an external medium at $\mathrm{pH} 7.3$ led to a fluorescence increase (Fig. 1a, b). $\mathrm{SpH}$ was subsequently removed from the plasma membrane by compensatory endocytosis of SVs whose re-acidification led to fluorescence decay back to baseline (Fig. 1a, b). In order to interrupt glutamate loading, we applied different known blockers of VGLUTs. We found that the most common VGLUT inhibitor Evans Blue ${ }^{25}$ is not suitable to impact SV acidification due to its membrane impermeability (Supplementary Fig. 1). In contrast, Rose Bengal (RB), a potent noncompetitive inhibitor of VGLUTs is membrane permeant ${ }^{26,27}$. In presence of the scavenger histidine to protect neurons from singlet oxygen production during illumination $^{28}$ (Supplementary Fig. 2), inhibition of VGLUT with $\mathrm{RB}$ induced a partial loss of $\mathrm{SpH}$ fluorescence recovery (Fig. 1a, c).

Next, we distinguished between $\mathrm{SpH}$ signals from GABAergic and glutamatergic neurons using antibodies directed against the luminal domain of the vesicular GABA transporter (VGAT) coupled to the $\mathrm{pH}$-sensitive fluorescent dye CypHer5E ( $\alpha$ VGATCypHer) ${ }^{29}$ (Fig. 1e). Contrary to pHluorin, CypHer5E is quenched at neutral $\mathrm{pH}$. Therefore, electrical stimulation triggered a transient decrease in $\alpha$ VGAT-CypHer fluorescence signals (Fig. 1d). Using dual-colour experiments with $\mathrm{SpH}$ and $\alpha$ VGAT-CypHer, we found that RB strongly and specifically affected glutamatergic but not GABAergic boutons (Fig. 1d, f), and thus not the V-ATPase at the low concentration (100 nM) used here ${ }^{26}$. In addition, RB did neither change exo-endocytosis rate (Supplementary Fig. 3a-c), nor affect SV recycling (Supplementary Fig. 3d, e). Thus, specific VGLUT inhibition by $\mathrm{RB}$ abrogated SV acidification. In addition to SV re-acidification inhibition, RB induced a transient post-stimulation SV alkalinisation (Fig. 1f, g) caused by exocytosis of V-ATPases (Supplementary Fig. 4) that transiently alkalinized cytosolic $\mathrm{pH}^{30}$, suggesting that VGLUT inhibition renders SV sensitive to cytosolic $\mathrm{pH}$ changes.

VGLUT exchanges chloride for glutamate in SVs. We so far demonstrated that uptake of glutamate into SVs is necessary for generation and maintenance of the $\mathrm{pH}$ gradient, arguing that VGLUT and V-ATPase activities are functionally coupled in neurons. However, no direct molecular interaction or indirect signalling mechanism between both proteins has been described. We therefore investigated whether an electrical coupling by ions other than protons might link uptake of glutamate and vesicular acidification. Consistently, glutamatergic SV from VGLUT1deficient mice showed normal $\mathrm{SpH}$ fluorescence transients upon stimulation and $\mathrm{RB}$ no longer blocked their re-acidification (Fig. 2a), indicating that the coupling is abolished in absence of the transporter. Interestingly, VGLUT1 itself has been shown to conduct $\mathrm{Cl}^{-17,24}$. This exchange might occur through two independent binding sites ${ }^{23}$, thus $\mathrm{Cl}^{-}$transport might be unaffected by the RB block. Such an exchange of $\mathrm{Cl}^{-}$for negatively charged glutamate would be electrically neutral under control conditions (one glutamate for one $\mathrm{Cl}^{-}$), but inhibition of glutamate transport alone would result in a positive $\Delta \Psi$ by efflux of luminal $\mathrm{Cl}^{-}$, sufficiently positive to block the voltage-dependent $\mathrm{V}$-ATPase, thereby preventing acidification. In order to study the putative role of luminal $\mathrm{Cl}^{-}$, we abolished the $\mathrm{Cl}^{-}$gradient 

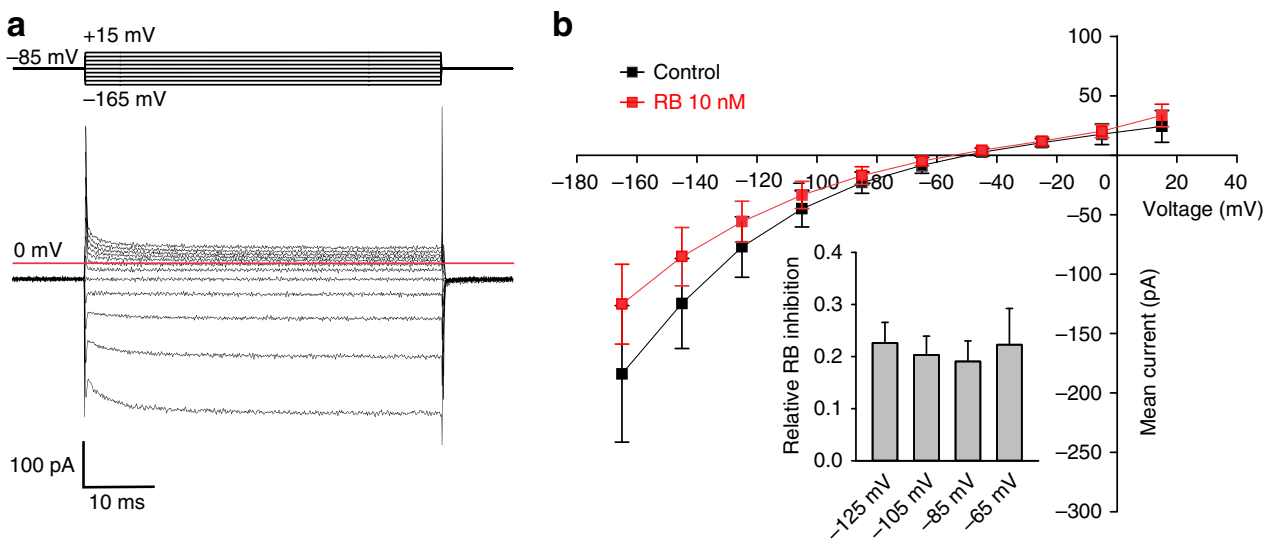

Fig. 3 RB has only minor effects on VGLUT1 $\mathrm{Cl}^{-}$currents. a Representative current responses from HEK cells expressing internalization-defective VGLUT1 to voltage steps from $-165 \mathrm{mV}$ to $+15 \mathrm{mV}$ in $20 \mathrm{mV}$ increments from a holding potential of $-85 \mathrm{mV}$. b Mean current voltage relationships from VGLUT1 in the absence (black square $n=5$ ) and in the presence (red square $n=5$ ) of $10 \mathrm{nM} \mathrm{RB}$. Inset, relative RB inhibition at different voltages. Error bars represent s.e.m

between the vesicular lumen and the neuronal cytosol ${ }^{31,32}$ by decreasing the extracellular $\mathrm{Cl}^{-}$concentration. Substitution of $\mathrm{Cl}^{-}$ by an equimolar concentration of iodide affected neither SV cycling nor re-acidification (Supplementary Fig. 5). However, most $\mathrm{Cl}^{-}$conductances exhibit low selectivity among inorganic anions ${ }^{33}$. Thus, to suppress any putative anion conductance, $\mathrm{Cl}^{-}$ was then substituted by either gluconate $\left(\mathrm{Gluc}^{-}\right)$or methanesulfonate $\left(\mathrm{MeS}^{-}\right)$, large impermeant anions ${ }^{34}$. Both anions, however, display very different proton buffer capacities ( $\mathrm{pKa}$ of 3.7 for $\mathrm{Gluc}^{-}$and $\mathrm{pKa}$ of -1.2 for $\mathrm{MeS}^{-}$, respectively). Thus, the HEPES concentration was also varied for compensation. With appropriate HEPES concentrations substitution of $\mathrm{Cl}^{-}$with either Gluc ${ }^{-}$or $\mathrm{MeS}^{-}$reversed the acidification block induced by RB (Fig. 2b), i.e. it disrupted the electrical coupling of glutamate transport to $\mathrm{H}^{+}$pumping observed in the presence of RB (Figs. if and $2 \mathrm{~b}$ ). Since $\mathrm{SpH}$ response amplitudes for both GABAergic and glutamatergic boutons were reduced during $\mathrm{Cl}^{-}$substitution (Supplementary Fig. 6a-d) without affecting exo-endocytosis rates (Supplementary Fig. 6f), and re-acidification in GABAergic boutons (Supplementary Fig. 6e) ${ }^{35}, \mathrm{SpH}$ traces were normalized to their respective fluorescence values at the end of the stimulation. We conclude that in order to phenocopy the full reacidification observed in the VGLUT1-deficient mice, block of glutamate transport by RB is not sufficient, but in addition the vesicular $\mathrm{Cl}^{-}$gradient has to be abolished (Fig. 2), thus revealing a channel-like $\mathrm{Cl}^{-}$conductance of VGLUT1 17 also in recycling SVs, similar to what has been observed for plasma membrane glutamate transporters of the excitatory amino acid transporter (EAAT) family ${ }^{36}$. Overall, these data show that $\mathrm{Cl}^{-}$efflux is mostly responsible for the initial $\Delta \Psi$ generation necessary for glutamate transport at neutral $\mathrm{pH}$ at the beginning of $\mathrm{SV}$ refilling. Usually this $\Delta \Psi$ build-up is partially shunted by onsetting glutamate uptake, but in the presence of RB (Figs. If and 2b) this shunt is blocked, such that $\Delta \Psi$ quickly reaches a value which stalls the voltage-dependent V-ATPase activity. In boutons from VGLUT1-deficient neurons this $\mathrm{Cl}^{-}$-dependent $\Delta \Psi$ build-up is absent, thus re-acidification is normal (Fig. 2a). To directly demonstrate the existence of a chloride conductance in the presence of RB, we heterologously expressed mutant VGLUT1 that was optimized for surface membrane insertion in HEK293T cells ${ }^{17}$ and performed whole-cell patch-clamp recordings at $\mathrm{pH} 5.0$ in the absence as well as in the presence of RB. To assess the effect of $\mathrm{RB}$ on chloride efflux out of the synaptic vesicles, we established an anion gradient with a cytoplasmic $[\mathrm{Cl}$ $\left.{ }^{-}\right]_{\text {int }}$ of $14 \mathrm{mM}$ and an external $\left[\mathrm{Cl}^{-}\right]$of $145 \mathrm{mM}$ (corresponding to the high anion concentration in the vesicle after endocytosis). Under these conditions, we observed an inwardly rectifying chloride current that reversed close to the calculated anion reversal potential (Fig. 3a). RB resulted only in a reduction of anion currents (Fig. 3b).

To further confirm the pivotal role of the $\mathrm{Cl}^{-}$conductance of VGLUT1 in SV refilling, we aimed to investigate the $\mathrm{Cl}^{-}$ concentration inside glutamatergic SV from wild-type and VGLUT1-deficient mice. First, we designed a vesicular chloride sensor based on the previously described ratiometric indicator of $\mathrm{pH}$ and $\mathrm{Cl}^{-}$by excitation ClopHensorN ${ }^{37}$ fused to the luminal domain of synaptobrevin 2. However synaptobrevin 2ClopHensor was mistargeted and numerous aggregates could be observed in the neuronal cell bodies and axons. Thus, we coupled ClopHensorN to the luminal domain of synaptotagmin 1 (SytClopH) (Fig. 4a). When expressed in cultured hippocampal neurons, SytClopH exhibited a punctate distribution corresponding to its targeting to synapses (Fig. 4d). The calibration of SytClopH at various $\mathrm{pH}$ and $\left[\mathrm{Cl}^{-}\right]$values by ionophore clamping technique (Methods) indicated that the vesicular sensor conserved the properties described for the cytosolic ClopHensorN (Fig. 4b, c and Supplementary Fig. 7) ${ }^{37}$. A tobacco etch virus (TEV) protease cleavage site was present between synaptotagmin 1 and the ClopHensorN moieties. This site is only accessible to external enzyme if SytClopH is in the plasma membrane. Proteolytic cleavage of ClopHensorN from the plasma membrane led to a virtually pure vesicular expression of SytClopH (Fig. 4a) allowing us to directly measure the luminal $\mathrm{pH}$ and chloride concentration of SV. The measured $R_{\mathrm{pH}}$ showed a similar acidic $\mathrm{pH}$ in the lumen of both wild-type and VGLUT1-deficient mice (Fig. 4e). The $R_{\mathrm{Cl}}$ measured in SV from wild-type mice indicated that the average glutamatergic luminal $\left[\mathrm{Cl}^{-}\right]$was $14.7 \pm 2.50 \mathrm{mM}$ (Fig. 4f), similar to the $\left[\mathrm{Cl}^{-}\right]$within the neuronal cytosol ${ }^{31,32}$. The absence of a chloride gradient between the SV lumen and the cytosol at resting state is consistent with an efflux of endocytosed chloride during SV recycling $\left(\sim 130 \mathrm{mM}\right.$ extracellular $\left[\mathrm{Cl}^{-}\right]$upon vesicle formation). On the opposite, the average $R_{\mathrm{Cl}}$ measured in SV from VGLUT1-deficient mice was significantly smaller than $R_{\mathrm{Cl}}$ from wild-type animals, indicating that in absence of VGLUT1 the luminal $\left[\mathrm{Cl}^{-}\right]$is much higher and reaches values in the saturation range of SytClopH $(>90 \%$ saturation, i.e. $>88.3$ $\mathrm{mM}$ ) (Fig. 4f). The significant difference in luminal $\left[\mathrm{Cl}^{-}\right]$from wild-type and VGLUT1-deficient mice demonstrates that VGLUT1 itself is responsible for the effective removal of luminal $\mathrm{Cl}^{-}$during SV recycling down to the low cytosolic concentration. 
Our results imply that SVs are loaded with about $120 \mathrm{mM}$ glutamate under isosmotic conditions.

Luminal proton buffer capacity. The most common impermeant anion used to substitute $\mathrm{Cl}^{-}$is $\mathrm{Gluc}^{-}$. However, unlike $\mathrm{MeS}^{-}$used earlier, $\mathrm{Gluc}^{-}$possesses a small proton-buffering capacity leading to more complex dynamics of re-acidification which critically depend on the HEPES concentration, thus on exogenous proton buffer capacity. For the normal HEPES concentration of $25 \mathrm{mM}$ used here, $\mathrm{SpH}$ fluorescence signals of glutamatergic boutons never returned to baseline after stimulation when $\mathrm{Cl}^{-}$was progressively substituted by Gluc (Fig. 5a, c). This lack of acidification would be expected if the endocytosed $\mathrm{Cl}^{-}$concentration controlled the final vesicular glutamate content ${ }^{23}$. With reduced or completely absent $\mathrm{Cl}^{-}$efflux, glutamate uptake is restricted by osmotic pressure. Thus, less glutamate would be loaded, which in turn would shunt $\Delta \Psi$ increasingly less efficiently, thereby restraining more and more $\mathrm{H}^{+}$influx. V-ATPase pumping would cease as soon as the membrane capacitance was charged up and $\Delta \Psi$ became too positive. The degree of acidification reached at steady state then simply would depend on the total $\mathrm{H}^{+}$buffering capacity inside the SV. In line with this, decreasing the total luminal buffering capacity by reducing HEPES concentration allowed complete acidification in presence of high $\mathrm{Gluc}^{-}$concentrations (Fig. 5b). The $\mathrm{H}^{+}$buffering capacity of $119 \mathrm{mM} \mathrm{Gluc}^{-}$ $(\mathrm{pKa}$ of 3.7) at $\mathrm{pH} 5.6$ corresponds roughly to the buffering capacity of a few mM HEPES (pKa of 7.55). Thus, a reduction to $20 \mathrm{mM}$ HEPES led already to re-acidification to $\mathrm{pH} 6.3$, and a reduction to $5 \mathrm{mM}$ HEPES to full re-acidification (Fig. 5e). Accordingly, substitution by $\mathrm{MeS}^{-}$which has no $\mathrm{H}^{+}$buffering capacity (pKa of -1.2) led to full re-acidification even in presence of $25 \mathrm{mM}$ HEPES (Fig. 5d). These data show that $\mathrm{Cl}^{-}$efflux from the vesicular lumen controls the reacidification kinetics, which are considered to be a proxy for glutamate loading. Thus, $\mathrm{Cl}^{-}$efflux appears to control the amount of glutamate loaded into SVs in line with a previous study ${ }^{23}$, and thereby also the final $\mathrm{H}^{+}$concentration. As a consequence, the degree of acidification depends on the intravesicular $\mathrm{H}^{+}$buffering capacity.

VGLUT is a glutamate/ $\mathrm{H}^{+}$exchanger. To further characterize the role of $\mathrm{Cl}^{-}$and $\mathrm{H}^{+}$flux coupling for glutamate loading, we next analysed the acidification kinetics using the 'rapid acid quench' strategy ${ }^{38}$. In this paradigm, the membrane of hippocampal neurons expressing $\mathrm{SpH}$ was quenched by acidic buffer shortly after a train of electrical stimulation (Fig. 6). Newly endocytosed $\mathrm{SpH}$ in not-yet acidified SV was protected from the surface quench while subsequent compensatory endocytosis was masked by acid. Therefore, the fluorescence decay during the quench, absent if not stimulated, directly reflects re-acidification kinetics (Fig. 6b, c). The time course of re-acidification is well approximated by a mono-exponential with a time constant of 4.9 $\pm 0.3 \mathrm{~s}$. Notably, neither histidine nor HEPES at the concentrations used (up to $25 \mathrm{mM}$ ) influenced significantly the time course of re-acidification (compare with controls without histidine in Fig. 7 and Supplementary Fig. 8). However, with $40 \mathrm{mM}$ HEPES the SV re-acidification is somewhat slowed down (Supplementary Fig. 8), suggesting that the endogenous buffer capacity roughly equals that of a few $10 \mathrm{mM}$ HEPES. This is in line with a recent theoretical estimate of the luminal buffer capacity provided by the $\sim 560$ glutamate and $\sim 150$ histidine residues in the luminal protein matrix, yielding a buffer capacity of $10-15 \mathrm{mM}$ per $\mathrm{pH}$ unit $^{39}$. The impact of high $\mathrm{mM}$ of exogenous buffer on the reacidification rate is confirmed by the use of TRIS as an alternate proton buffer (Supplementary Fig. 8). Consistent with Fig. 1f, in presence of $\mathrm{RB}$, the fluorescence during acid quench did not a
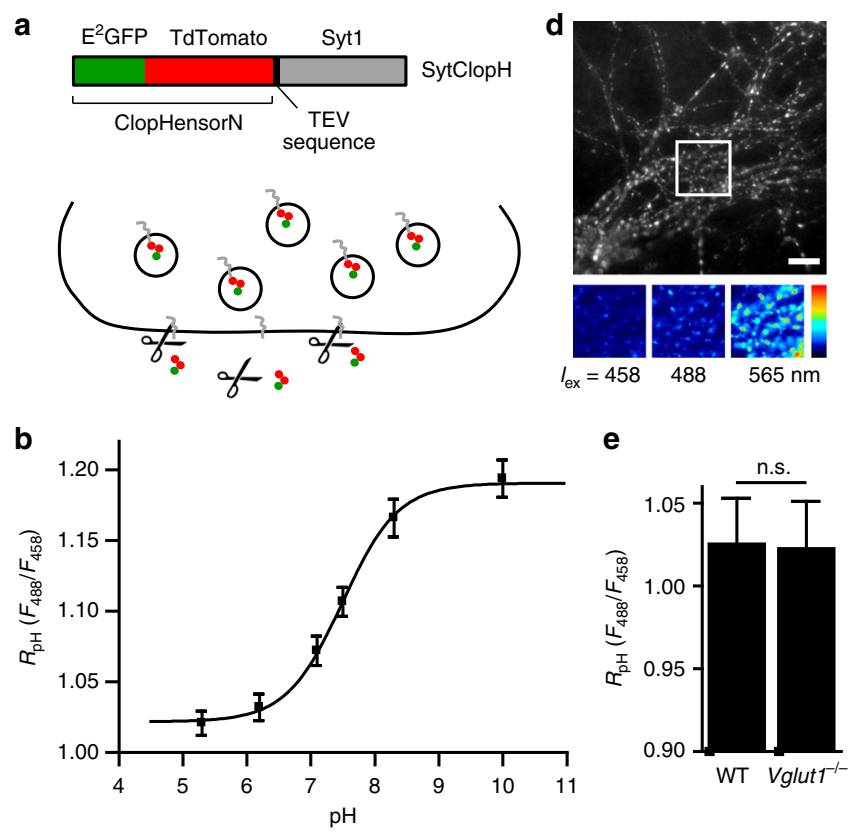

c

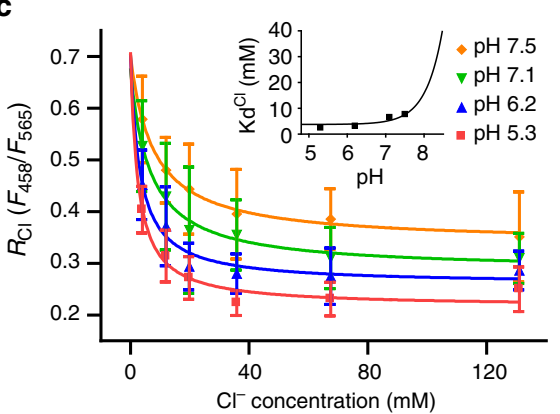

f

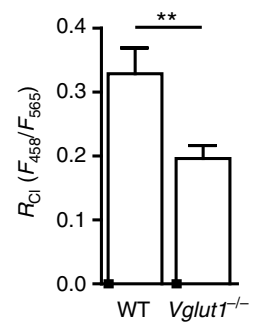

Fig. 4 Absence of VGLUT1 prevents the efflux of luminal $\mathrm{Cl}^{-}$. a The synaptotagmin 1-ClopHensorN (SytClopH) construct is composed of the previously described ClopHensorN (E ${ }^{2}$ GFP-TdTomato fusion) ${ }^{37}$ fused to the cleavage site for recombinant TEV protease and synaptotagmin 1 (Syt1) (top). When neurons-overexpressing SytClopH were exposed to $60 \mathrm{U} \mathrm{ml}^{-1}$ TEV protease (scissors) at room temperature, ClopHensorN was cleaved from molecules residing in the plasma membrane while vesicular SytClopH was inaccessible to the protease (bottom). b SytClopH calibration curve relating $\mathrm{pH}$ to the ratio of fluorescence emission when $\mathrm{E}^{2} \mathrm{GFP}$ was excited at $488 \mathrm{~nm}$ over the emission when excited at $458 \mathrm{~nm}\left(R_{\mathrm{pH}}\right)$. pKa was found to be 7.49 with a fitted $95 \%$ confidence interval between 7.23 and 7.76 . Note that variation of $\mathrm{Cl}^{-}$concentration within the physiological range had no effect on $\mathrm{RpH}$ (Supplementary Fig. 7). c SytClopH calibration curve relating $\mathrm{Cl}^{-}$concentration to the ratio of fluorescence emission when $E^{2} \mathrm{GFP}$ was excited at $458 \mathrm{~nm}$ over the emission when TdTomato was excited at $565 \mathrm{~nm}\left(R_{\mathrm{Cl}}\right)$. Change in $\mathrm{pH}$ influences the affinity of SytClopH for $\mathrm{Cl}^{-}$. d Fluorescence image of hippocampal axonal arborisations of wild-type neurons expressing SytClopH collected following excitation at $565 \mathrm{~nm}$. The insets (bottom) show a higher magnification with excitation at 458,488 and $565 \mathrm{~nm}$ respectively. Scale bar represents $10 \mu \mathrm{m}$. e, f Histogram of the measured $R_{\mathrm{pH}}(\mathbf{e})$ and $R_{\mathrm{Cl}}(\mathbf{f})$ in hippocampal neurons from wild-type (WT, $n=29)$ and VGLUT1 knock-out (Vglut $1^{-/}, n=27$ ) mice. n.s. not significant $P=0.9447 ;{ }^{\star \star} P=0.0060$ analysed with two-tailed unpaired $t$-test. Error bars represent s.e.m

decay and had a higher intensity compared to background, revealing an alkaline, not re-acidified pool of endocytosed SVs (Fig. 6c).

As might be expected from the slow decay kinetics observed for Gluc $^{-}$and $\mathrm{MeS}^{-}$substitution (Fig. 5), SV acidification determined with the acid quench was significantly slowed by $\mathrm{Cl}^{-}$removal 

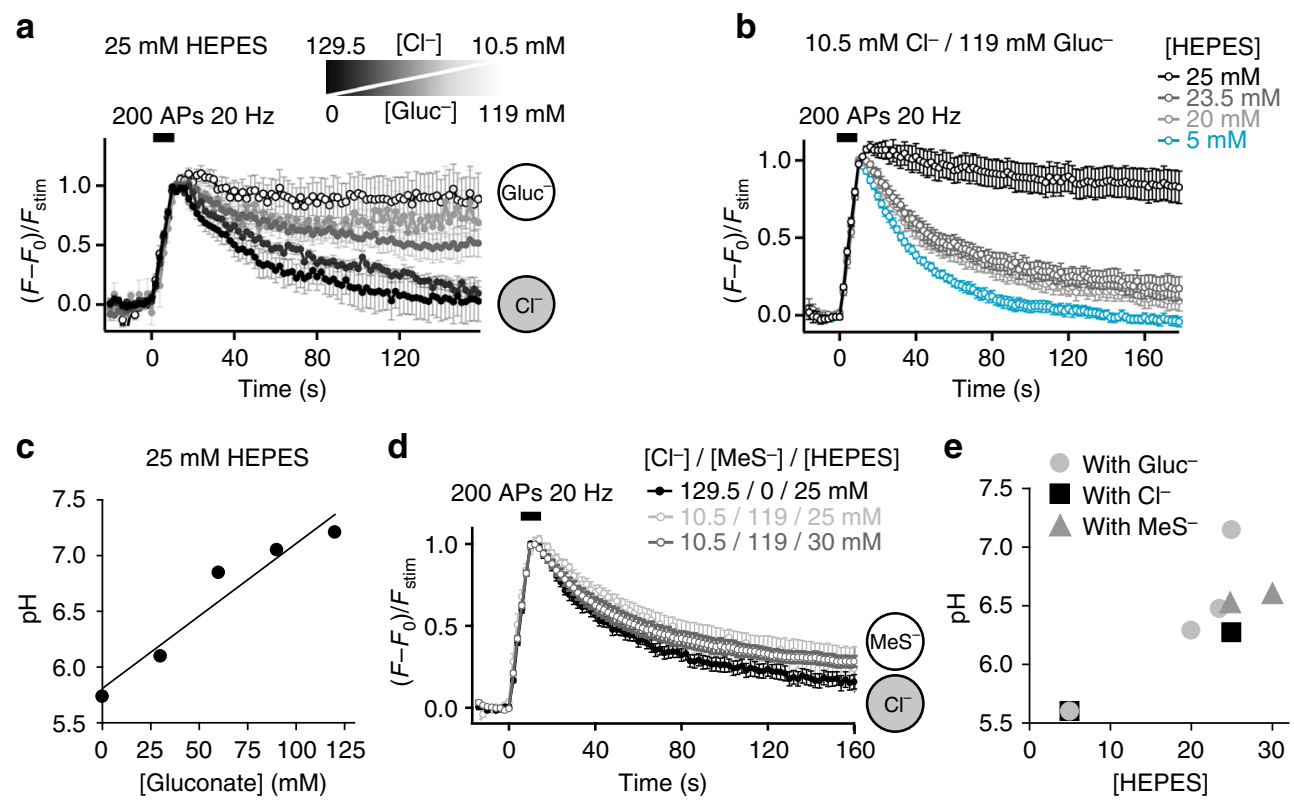

Fig. 5 Dependence of SV acidification on luminal buffering capacity. a Average $\mathrm{SpH}$ transients in response to stimulation (200 APs, $20 \mathrm{~Hz}$ ) in neurons exposed to different combinations of extracellular chloride/gluconate concentrations $\left(\left[\mathrm{Cl}^{-}\right] /\left[\mathrm{Gluc}^{-}\right]\right)(n=3-10)$. $\mathrm{Cl}^{-}$concentration is decreased from $129.5 \mathrm{mM}$ (black) to $100-70-40-10.5 \mathrm{mM}$ while being substituted by $\mathrm{Gluc}^{-}$to maintain a final anion concentration of $129.5 \mathrm{mM}$. The sketches show the main anion present in SV. b Average SpH fluorescence responses to $200 \mathrm{APs}$ at $20 \mathrm{~Hz}$ in presence of $10.5 \mathrm{mM} \mathrm{Cl}^{-}, 119 \mathrm{mM} \mathrm{Gluc}^{-}$and different $\mathrm{HEPES}^{-}$ concentrations as indicated $(n=6-14)$. $\mathbf{c}$ Luminal pH of SVs endocytosed with various Gluc ${ }^{-}$concentrations, estimated from the plateaus reached in a. $\mathbf{d}$ Average $\mathrm{SpH}$ responses to stimulation (200 APs, $20 \mathrm{~Hz}$ ) in neurons exposed to different HEPES concentrations and different combinations of extracellular chloride/methanesulfonate concentrations $\left(\left[\mathrm{Cl}^{-}\right] /\left[\mathrm{MeS}^{-}\right]\right)(n=7-16)$. The sketches show the main anion present in SV. e Luminal pH of SVs endocytosed with various HEPES and ion concentrations, estimated from the plateaus reached in $\mathbf{a}, \mathbf{b}, \mathbf{d}$. Traces in $\mathbf{a}, \mathbf{b}, \mathbf{d}$ represent responses of glutamatergic boutons only. Error bars represent s.e.m

(Fig. 7). Most notably, the acidification kinetics were equally slow, irrespective of the substitute $\left(\mathrm{Gluc}^{-}\right.$or $\mathrm{MeS}^{-}$) or HEPES concentration used, i.e. irrespective of the $\mathrm{H}^{+}$buffer capacity and the steady state $\mathrm{pH}$ reached. This finding implies that $\mathrm{H}^{+}$ influx through the V-ATPase is mostly shunted away by a $\mathrm{H}^{+}$ efflux of almost equal size, and that the acidification kinetics merely reflect the time for reaching a steady state.

In order to unmask this massive $\mathrm{H}^{+}$antiport associated with VGLUT activity, we investigated the re-acidification kinetics under conditions where VGLUT and V-ATPase activities are uncoupled: VGLUT1 knockout or $\mathrm{RB}$ plus $\mathrm{Cl}^{-}$substitution. In the absence of $\mathrm{Cl}^{-}$efflux and glutamate influx, acidification was accelerated by at least an order of magnitude (Fig. 8). A deficit in endocytosis and/or acidification in VGLUT1 knockout synapses as alternative explanation could be ruled out. First, the $\mathrm{SpH}$ fluorescence fully recovered to baseline (Fig. 2a). Second, the plateaus during the acid quench with and without stimulation, i.e. with and without exo-/endocytosis of synaptic vesicles, were identical indicating that all vesicles have been re-acidified to steady state (Fig. 8c). Interestingly, under these uncoupling conditions the $\mathrm{H}^{+}$flux through the V-ATPase can directly build up the $\mathrm{pH}$ gradient and the degree and kinetics of acidification only depend on the luminal $\mathrm{H}^{+}$buffering capacity and the electrical membrane capacity. Indeed, lowering the concentration of HEPES from $25 \mathrm{mM}$ to $5 \mathrm{mM}$ now led to an even faster acidification, not easily distinguishable from the solution exchange time course during acid quench (Fig. 8b inset and 8e).

\section{Discussion}

Using hippocampal neurons in culture, $\mathrm{Cl}^{-}$- and $\mathrm{pH}$-sensitive fluorescent sensors, we found that in SVs VGLUT1 functions as a glutamate $/ \mathrm{H}^{+}$exchanger associated with a stoichiometrically uncoupled $\mathrm{Cl}^{-}$conductance. As a consequence, $\mathrm{Cl}^{-}$taken up during endocytosis fuels $\Delta \Psi$-driven glutamate uptake and consequently controls SV acidification velocity (Fig. 9). In the beginning of SV recycling, there is no proton gradient and considering the SV volume, a pH of 7.3 corresponds to only $0.5 \%$ of a single free proton. VGLUT1 is a voltage- and $\mathrm{H}^{+}$-dependent antiporter, i.e. in order to pump glutamate it needs either a positive voltage or (at lower voltage) a proton gradient. At first, it is thus the $\Delta \Psi \mathrm{Cl}$ that drives VGLUT1, and $\sim 10$ transporters per SV pump as much $\mathrm{H}^{+}$out as the $\sim 1.5 \mathrm{~V}$-ATPases per SV pump in. The high voltage $(\Delta \Psi \mathrm{Cl})$ also impedes the V-ATPase pumping speed, thus the V-ATPase just keeps pace with the VGLUTs. As the $\mathrm{Cl}^{-}$gradient decreases VGLUTs slow down, but this is now compensated by the accelerating V-ATPase activity which leads to a VGLUT1-stimulating $\mathrm{pH}$ decrease. Still, at this point, essentially every $\mathrm{H}^{+}$pumped in by the $\mathrm{V}$-ATPase is transported out by VGLUT1 (even pH 5.5 corresponds to only $5 \%$ of one free proton) in exchange to glutamate. Thus, as $\Delta \Psi \mathrm{Cl}$ vanishes, $\Delta \Psi \mathrm{H}$ builds up and takes over the energizing glutamate transport, allowing the V-ATPase to acidify the lumen of the vesicle. Coupling glutamate influx with $\mathrm{Cl}^{-}$efflux as counter anion ensures osmotic and electrical neutrality of the vesicular filling process, and in the first place enables concentrating glutamate up to an isosmotic, i.e. maximum concentration of up to 1800 molecules in the $\mathrm{SV}^{40}$.

Our results show that the electrical coupling between acidification and glutamate transport reflects a glutamate $/ \mathrm{H}^{+}$ exchange mechanism for VGLUT activity (Fig. 9). The massive $\mathrm{H}$ + antiport associated with VGLUT activity enabled us to infer the glutamate transport rates and properties from the SV acidification measurement. We thus demonstrated that vesicular acidification rates scale with luminal chloride concentrations, in accordance with the fact that high chloride concentration in VGLUT1containing proteoliposomes enhanced glutamate transport 
a

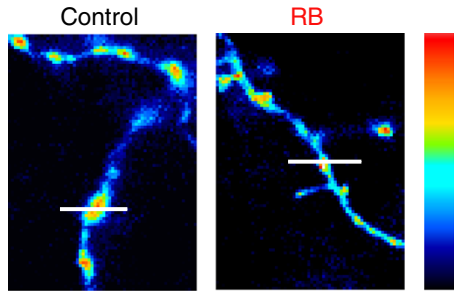

b

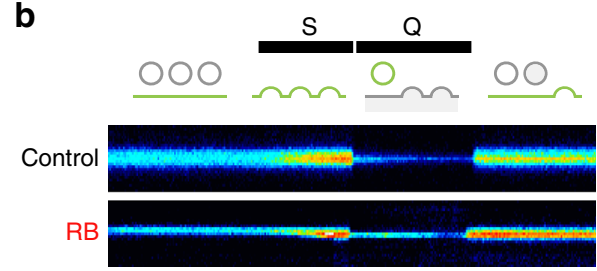

C

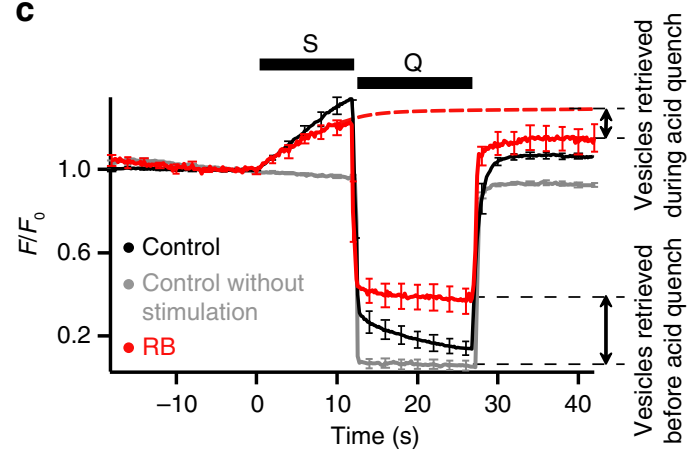

Fig. 6 Time course of SV acidification. a SpH fluorescence of axons and presynaptic terminals after stimulation $(12 \mathrm{~s}, 20 \mathrm{~Hz})$ in control conditions or after 5 min incubation with $100 \mathrm{nM} \mathrm{RB}$. Lines represent the position of the scan lines in $\mathbf{b}$. $\mathbf{b}$ Line-scan time series of single boutons. S: field electrical stimulation, Q: rapid surface quenching by application of impermeant acid (pH 5.25) immediately after end of stimulation. Pseudo-colour scale bars $\mathbf{a}$, b are linear, with black indicating zero fluorescence. Schematic shows the fluorescence of three SVs recaptured at different rates: before, during and after acid quench (from left to right) in control conditions. c Average SpH responses without $(n=10)$ or with stimulation in absence $(n=11)$ or presence $(n=6)$ of RB. Red dashed line represents the average $\mathrm{SpH}$ response in presence of $\mathrm{RB}$, without acid quench. Time scale is the same in b and $\mathbf{c}$. Error bars represent s.e.m. They are shown every tenth point ( $2 \mathrm{~s}$ ) for better visibility

rates $^{23}$. Accordingly, in control conditions the acidification time constant does not depend on HEPES concentration, which was previously observed but interpreted as an exclusion of HEPES from SV undergoing endocytosis or the inability of buffering $\mathrm{H}^{+}$ in the microenvironment of $\mathrm{SV}^{38}$. A few $\mathrm{mM}$ of HEPES or TRIS can already increase sufficiently the buffering capacity of SVs and induce slower acidification. Although TRIS has a higher $\mathrm{pKa}$ than HEPES (8.3 and 7.55 respectively) and thus a higher buffering potency, HEPES affected the reacidification kinetics more at 5 $\mathrm{mM}$, in line with a previous observation ${ }^{38}$. It is unclear what property, their charge or size, is responsible for this difference.

The glutamate/ $\mathrm{H}^{+}$exchange facilitates the transport of glutamate against its gradient and fuels this transport when the $\mathrm{Cl}^{-}$ gradient vanishes. Without this strictly coupled proton antiport SVs could only be filled half, i.e. up to the point where $\mathrm{Cl}^{-}$and glutamate gradients are equal and opposite in direction. Accordingly, V-ATPase inhibition decreases glutamatergic evoked and miniature excitatory postsynaptic currents in cultured hippocampal neurons although the chloride conductance produces most of the $\Delta \Psi$ required for glutamate loading ${ }^{41,42}$. The glutamate refilling process therefore can be separated into two phases. Initially the $\mathrm{Cl}^{-}$gradient is large and thus $\Delta \Psi$ is high, close to the $\mathrm{Cl}^{-}$reversal potential. Under this high- $\Delta \Psi$ condition the voltage-dependent V-ATPase activity is low, while the VGLUT activity is high and fuelled mostly by the $\mathrm{Cl}^{-}$conductance. Most protons imported by the V-ATPase are exported by the VGLUT1 transporters. When the $\mathrm{Cl}^{-}$gradient, however, decreases towards half its initial value, $\Delta \Psi$ would vanish. But this decreasing membrane potential now disinhibits the V-ATPase so that further glutamate can be transported in this second phase. Although the membrane potential further drops VGLUT activity is now maintained by progressively lowering $\mathrm{pH}$, i.e. V-ATPase activity at low membrane potential now exceeds that of VGLUT1. In this way the $\mathrm{Cl}^{-}$gradient can be further decreased down to close to zero. Eventually at $\mathrm{pH} 5.5$ the V-ATPase activity is blocked by the almost 100 -fold $\mathrm{H}^{+}$gradient, and the refilling process comes to an end.

In line with this notion SV acidification was strongly accelerated in VGLUT1-deficient mice. Previous experiments have reported that ATP in presence of glutamate induced a strongly reduced acridine orange fluorescence quenching in SVs isolated from VGLUT1-deficient compared to wild-type mice ${ }^{23}$. Acridine orange fluorescence quenching is often used as a proxy of SV acidification. Thus the authors concluded that the absence of VGLUT1 impaired acidification of isolated SVs, in apparent conflict with our results. However, due to the likely loss of all ion gradients during the isolation procedure, we expect a net influx of glutamate without any coupled anion efflux in wild-type isolated SVs. This accumulating negative charge could be dissipated by massive $\mathrm{H}^{+}$loading, leading to an even lower luminal $\mathrm{pH}$ compared to SVs in intact cells and isolated from VGLUT1-deficient neurons. Notably the acridine orange fluorescence quenching assay does not report absolute $\mathrm{pH}$ values, and acidification in isolated SVs requires minutes instead of seconds, supporting this notion. Finally, the discrepancy between living cells and isolated SVs might hint at another yet to be identified ion transport mechanism in SVs which can dissipate to some degree $\Delta \Psi$ generated by the V-ATPase in SVs in intact cells, but not in isolated SVs where the ionic composition is different. This may explain why we observe rapid acidification in the absence of VGLUT, while positive charge accumulation $(\Delta \Psi)$ in isolated SVs prevents further acidification.

The role of cations cannot be easily studied in living neurons, as their concentrations cannot be changed without massively affecting excitability and thus exo-endocytosis, or the ATP homeostasis when using ionophores. The role of $\mathrm{K}^{+}$and $\mathrm{Na}^{+}$, however, has been investigated on isolated vesicles. For instance, the modulatory effect of $\mathrm{K}^{+}$on glutamate uptake in isolated vesicles or proteoliposomes is abolished when $\mathrm{Cl}^{-}$is present in the lumen ${ }^{24}$. So even if we cannot exclude a role for $\mathrm{K}^{+}$at the end of the loading process when the $\mathrm{Cl}^{-}$gradient is abolished, we do not expect a major role of this cation under physiological conditions. Additionally, no effect of $\mathrm{Na}^{+}$on glutamate uptake could be detected in the reconstituted system ${ }^{24}$. Finally, VGLUT2 was shown to contain two independent machineries for the $\mathrm{Cl}$ ${ }^{-}$-dependent uptake of glutamate and the $\mathrm{Na}^{+}$-dependent uptake of phosphate ${ }^{20}$. Therefore, cations like $\mathrm{K}^{+}$and $\mathrm{Na}^{+}$are likely to have only minor effects if any, on VGLUT activity and glutamate transport.

When VGLUT and V-ATPase activities are uncoupled, measured acidification time constants scaled roughly proportionally to the respective exogenous buffering capacities (Fig. 8), corroborating the notion that the endogenous SV buffering system is rather small and of comparable size. Thus, with a reasonable estimate of the buffering capacity, i.e. the number of buffering molecules for the different conditions, we can quite well infer the 

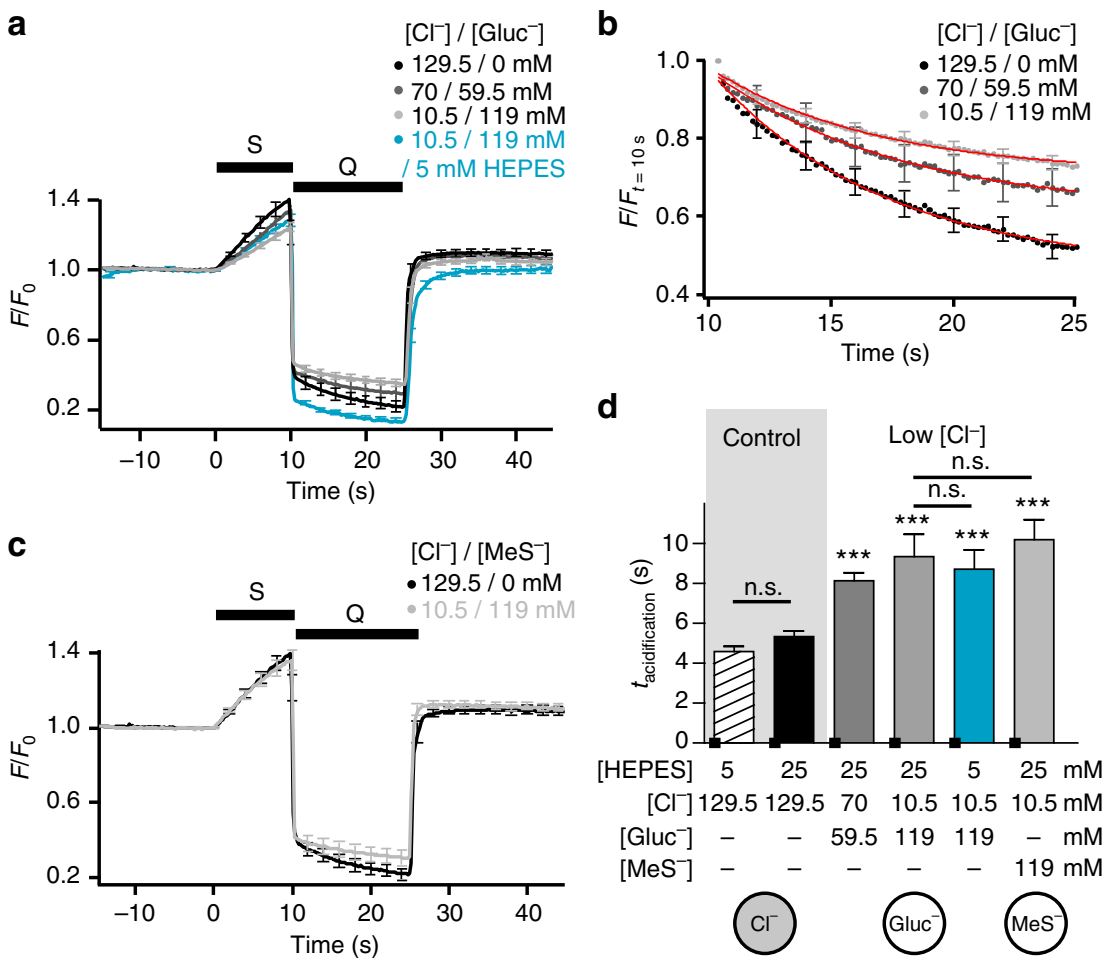

Fig. 7 Vesicular chloride controls the rate of acidification. a-c Rapid acid quench (Q) of surface SpH fluorescence following stimulation (S, 200 APs at 20 $\mathrm{Hz}$ ) in presence of different $\left[\mathrm{Cl}^{-}\right] /\left[\mathrm{Gluc}^{-}\right](\mathbf{a}, \mathbf{b})$ or $\left[\mathrm{Cl}^{-}\right] /\left[\mathrm{MeS}^{-}\right]$(c) with $25 \mathrm{mM} \mathrm{HEPES}$ unless otherwise stated $(n=8-17)$. b The fluorescence from SpH shown in a was normalized to the first data point measured during post-stimulus acid quench. Red curves: single exponential fits of the $\mathrm{SpH}$ fluorescence during the quench. d Bar graph of acidification time constants from experiments in a and c. $25 \mathrm{mM} \mathrm{HEPES:} P=0.0676$ compared with $5 \mathrm{mM}$ HEPES; 70 $\mathrm{mM} \mathrm{Cl}^{-} / 59.5 \mathrm{mM} \mathrm{Gluc}^{-}: P<0.0001$ compared with $25 \mathrm{mM} \mathrm{HEPES} ; 10.5 \mathrm{mM} \mathrm{Cl}^{-} / 119 \mathrm{mM} \mathrm{Gluc}{ }^{-}: P=0.0001$ compared with $25 \mathrm{mM}$ HEPES; $5 \mathrm{mM}$ HEPES/ $10.5 \mathrm{mM} \mathrm{Cl}^{-} / 119 \mathrm{mM} \mathrm{Gluc}^{-}: P<0.0001$ compared with $5 \mathrm{mM}$ HEPES, $P=0.6936$ compared with $25 \mathrm{mM} \mathrm{HEPES} / 10.5 \mathrm{mM} \mathrm{Cl}^{-} / 119 \mathrm{mM} \mathrm{Gluc}^{-} ; 10.5 \mathrm{mM} \mathrm{Cl}^{-}$ $-/ 119 \mathrm{mM} \mathrm{MeS}^{-}: P<0.0001$ compared with $25 \mathrm{mM} \mathrm{HEPES}, P=0.5703$ compared with $10.5 \mathrm{mM} \mathrm{Cl}^{-} / 119 \mathrm{mM} \mathrm{Gluc}^{-}$; analysed with two-tailed unpaired $t$ test. Sketches below show the main anion present in SV. Traces represent responses of glutamatergic boutons only. n.s. non significant; ${ }^{\star \star \star}$ significant changes. Error bars represent s.e.m. They are shown every tenth point $(2 \mathrm{~s})$ for better visibility

initial $\mathrm{H}^{+}$pumping rates from the acidification rate constants. Upon recycling, the $\mathrm{pH}$ of SV decreases from 7.3 to 5.5 . Within $\tau$ seconds the $\mathrm{SpH}$ fluorescence intensity drops to $1 / e$ of its initial value, which roughly corresponds to a drop in $\mathrm{pH}$ to about 6.4 according to the measured $\mathrm{pH}$-dependence of $\mathrm{pHluorin}^{43}$. SVs have an internal volume of $20 \times 10^{-21} \mathrm{l}^{40}$. Using the Henderson-Hasselbalch equation $\left(\mathrm{pH}=\mathrm{pKa}+\log \left(\left[\mathrm{A}^{-}\right] /[\mathrm{HA}]\right)\right)$ and taking into account $25 \mathrm{mM}$ HEPES $(\mathrm{pKa}=7.55)$ and $10 \mathrm{mM}$ histidine $(\mathrm{pKa}=6)$ as the only exogenous effective buffers (pHluorin itself with one to two copies per SV only ${ }^{44,45}$ and $\mathrm{MeS}^{-}$ are negligible), and $13 \mathrm{mM}$ histidine and $47 \mathrm{mM}$ glutamate $(\mathrm{pKa}=4)$ residues in the luminal protein matrix as relevant endogenous buffers ${ }^{39}$ we calculated that $\sim 150 \mathrm{H}^{+}$are bound to free buffer molecules during this time, while for the small SV volume the number of free protons is well below one molecule. With a time constant $\tau$ of $0.5 \pm 0.1 \mathrm{~s}$ (Fig. 8b, e) and $\sim 1.5$ copies of $\mathrm{V}$-ATPase per $\mathrm{SV}^{40}$ this suggests an initial $\mathrm{H}^{+}$pumping rate of $\sim 200 \mathrm{~s}^{-1}$ per V-ATPase, i.e. $\sim 34$ rotations per second of the $V_{0}$ subunits, well in the range of rates measured in vitro ${ }^{46}$. In another recent study the authors aimed at determining the vesicular proton buffer capacity by titration with different ammonium concentrations ${ }^{47}$. Using a simple buffer equation, assuming only mass balance for $\mathrm{NH}_{3}, \mathrm{NH}_{4}{ }^{+}$and protons inside and outside the vesicle, they arrived at a significantly higher estimate for the endogenous buffer capacity of $57 \mathrm{mM} \mathrm{NH}_{4}^{+}$per $\mathrm{pH}$ unit. However, this simple model neglects all other possible ion fluxes induced during titration, like by vATPase activity triggered by $\mathrm{pH}$ neutralization, and thus should lead to an overestimation of the buffer capacity.
Under control conditions, a final vesicular glutamate concentration of $120 \mathrm{mM}$ is exchanged for $120 \mathrm{mM} \mathrm{Cl}^{-}$according to our model, thus about 890 glutamate molecules would be loaded into a SV within $\tau \sim 5 \mathrm{~s}$. With about 10 VGLUTs per vesicle ${ }^{40}$, this yields an initial transport rate of $\sim 20$ molecules per second per transporter in intact neurons. Assuming the same $\mathrm{H}^{+}$transfer rate under control conditions, the measured acidification time constant of $\sim 5 \mathrm{~s}$ would imply an influx of $\sim 1500 \mathrm{H}^{+}$during this time. Taking into account the endogenous (histidine and glutamate) and exogenous (HEPES) buffers as well as the quantity of glutamate loaded, we found that $\sim 100 \mathrm{H}^{+}$are buffered in the lumen within $\tau$ seconds, also indicating that $\sim 1400 \mathrm{H}^{+}$are free. Since the electrical membrane capacitance of about $50 \mathrm{aF}$ per $\mathrm{SV}^{48,49}$ means that as few as $30 \mathrm{H}^{+}$generate already a membrane potential of $100 \mathrm{mV}$, most of this charge obviously must be shunted away by a $\mathrm{H}^{+}$efflux of roughly equal size, i.e. $1400 \mathrm{H}^{+}$. Considering that $\mathrm{Cl}^{-}$efflux initially impedes the V-ATPase pumping speed during glutamate loading and that the rough calculation of the total luminal buffer capacity is presumably underestimated $^{22,47}$, our data are compatible with a $1: 1$ to $1: 2$ stoichiometrically coupled glutamate $/ \mathrm{H}^{+}$exchange through VGLUT.

Based on its reconstitution in liposomes VGLUT1 has been proposed to exchange luminal chloride for glutamate through two independent binding sites, thereby stimulating glutamate transport ${ }^{23}$. In line, in a heterologous expression system a stoichiometrically uncoupled $\mathrm{Cl}^{-}$conductance has been revealed electrophysiologically ${ }^{17}$. Accordingly, we found that $\Delta \Psi$ generated by luminal chloride efflux was not blocked by RB 
(Figs. 1 and 3). Thus, the chloride transport must depend upon conformational changes distinct from those required for glutamate uptake, similar to the substrate-activated anion channel function found in membrane glutamate transporters of the EAAT family ${ }^{36}$. However, the finding of this anion conductance does not exclude a role for cytosolic chloride as an allosteric effector of VGLUT activity ${ }^{12,17,24}$.
In addition to VGLUT ClC-3 has been suggested to transport chloride in $\mathrm{SVs}^{50}$. ClC-3 is a $\mathrm{Cl}^{-} / \mathrm{H}^{+}$exchanger which has been proposed to provide a shunt for proton pump currents in SVs, thus allowing acidification ${ }^{50}$. As such, $\mathrm{ClC}-3$ could modulate VGLUT activity. The presence of $\mathrm{ClC}-3$ in glutamatergic SVs is still a matter of debate $e^{23,40,50}$. Nevertheless, by loading $\mathrm{Cl}^{-}$in SVs, ClC-3 would shunt the $\mathrm{Cl}^{-}$conductance of VGLUT, eventually dissipate $\Delta \Psi$ and subsequently stop VGLUT activity.

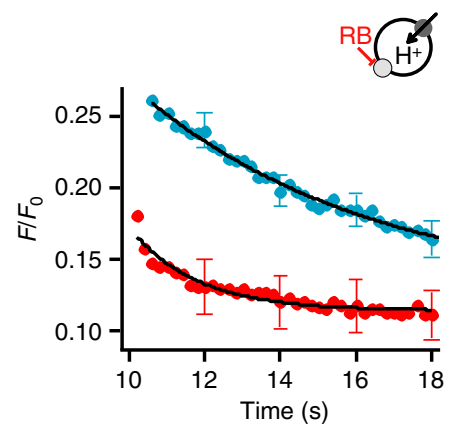

b

- 119 mM Gluc -15 mM HEPES - RB / $119 \mathrm{mM} \mathrm{Gluc}^{-}$/ 5 mM HEPES

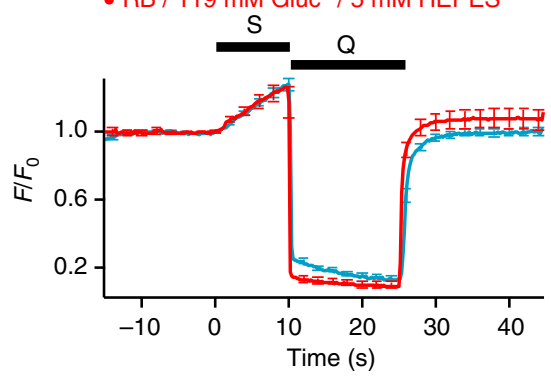

- $119 \mathrm{mM} \mathrm{MeS}^{-} / 25 \mathrm{mM}$ HEPES

- RB / 119 mM MeS- / 25 mM HEPES
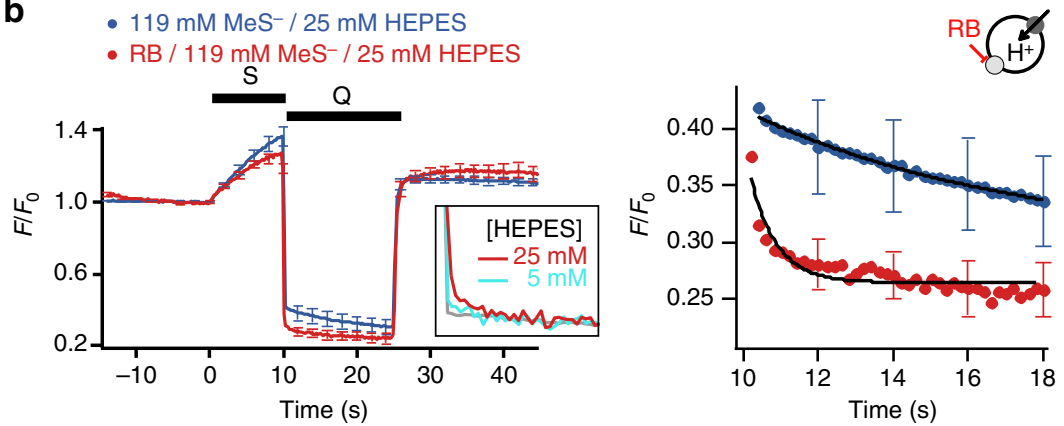

C

- Wild type

- Vglut1-1
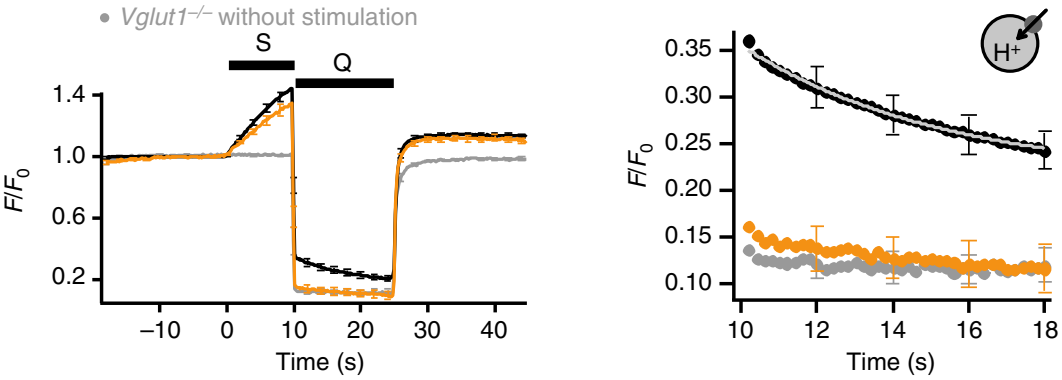

d

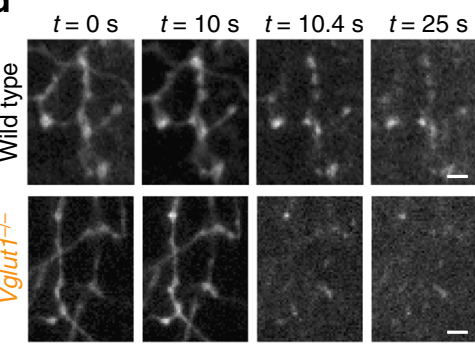

e

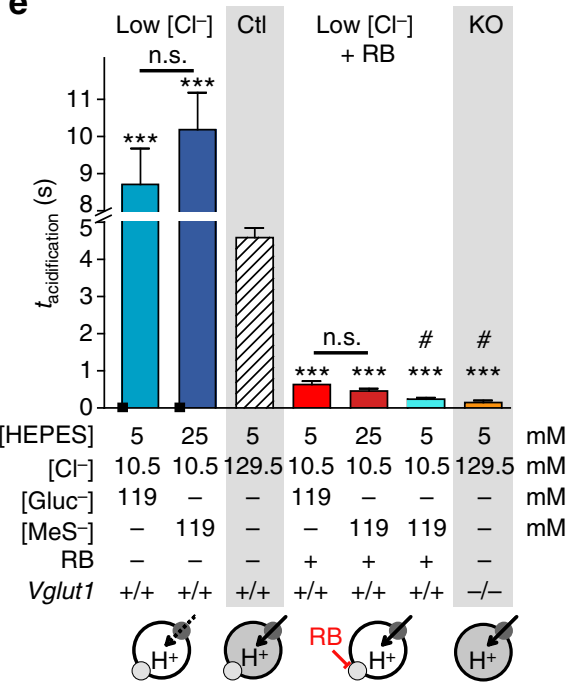


Accordingly, ClC- $3^{-/-}$mice show a slight increase in the amplitude and frequency of miniature excitatory postsynaptic currents as well as in the amplitude of evoked excitatory postsynaptic currents, suggesting an increase in vesicular glutamate filling consistent with the observed excitotoxicity and loss of the hippocampus formation ${ }^{51,52}$. Therefore, ClC-3 seems to fine tune and even rather restrain the glutamate loading into SVs.

Our kinetic data imply that one single VGLUT1 copy with a transport rate of $20 \mathrm{~s}^{-1}$ in conjunction with a single V-ATPase is sufficient to fully load a SV within $1 \mathrm{~min}$. Indeed, it has been shown in hypomorph VGLUT Drosophila mutants that a single transporter molecule suffices ${ }^{53}$. Other studies, however, showed that the neurotransmitter content is to some extent controlled by the transporter copy number ${ }^{5,6,27}$. This has been interpreted as a result of an equilibrium between glutamate uptake and leakage. Our finding of a channel-like $\mathrm{Cl}^{-}$conductance in VGLUT1 offers an alternative explanation: the final filling level could be controlled by modulating the $\mathrm{Cl}^{-}$fluxes, i.e. the amount of $\mathrm{Cl}^{-}$ flowing out in exchange for glutamate. The mechanism of vesicular glutamate transport is particularly interesting since VATPase was proposed to act as an acidification sensor in order to regulate exocytosis in hippocampal neurons and neurosecretory cells ${ }^{54}$. Because glutamate loading controls the rate of luminal acidification, V-ATPase not only senses the vesicular $\mathrm{pH}$ but it also indirectly senses whether the filling process is still ongoing or completed. Therefore, VGLUT signals to the exocytotic machinery whether a vesicle is ready for release using V-ATPase as an intrinsic link between vesicular fill state and fusion potency. Accordingly, the intravesicular glutamate fill state content was suggested to regulate SV release probability at hippocampal synapses in culture ${ }^{55}$.

Ever since the quantal hypothesis of transmitter release was proposed there has been lively debate about whether modulation of VGLUT activity might drive changes in synaptic strength. The glutamate $/ \mathrm{Cl}^{-}$exchange mode identified here represents an important means to control quantal content (Fig. 9d). The physiological as well as pathological conditions which lead to variations in extracellular and intravesicular $\mathrm{Cl}^{-}$remain to be determined in order to ascertain that these $\mathrm{Cl}^{-}$changes impact glutamatergic quantal size and consequently synaptic plasticity in vivo.

\footnotetext{
Methods

DNA construct. The original ClopHensorN construct ${ }^{37}$ was kindly provided by Colin Akerman (Addgene plasmid \#50758). A site-directed mutagenesis of ClopHensorN was performed to introduce a HindIII restriction site at the beginning of the ORF using the primers: SDM_ClopH_HindIII_fwd and SDM_ClopH_HindIII_rev (Supplementary Table 1). Then, a PCR was performed to add a XmaI restriction site at the end of the ClopHensorN-HindIII sequence using the primers: ClopH_HindIII_fwd and ClopH_XmaI_rev (Supplementary Table 1). The synaptotagmin 1-ClopHensorN (SytClopH) construct was finally made by replacing the pHluorin moiety from a synaptotagmin 1-TEV-pHluorin construct ${ }^{56}$ with the
}

cDNA encoding the ClopHensorN (Addgene). The new construct maintained the cleavage site for recombinant TEV protease (rTEV) flanked by spacer arms (amino acid sequence DYDIPTTLENLYFQGELKTVDAD). The construct was verified by dideoxynucleotide sequencing.

Cell culture. All animals were treated in accordance with the regulations and guidelines of the State of North Rhine-Westphalia. Dissociated cultures of hippocampal neurons were prepared from the CA3/CA1 region of 1- to 3-day-old CD1 wild-type or VGLUT1-deficient (purchased from the Mutant Mouse Regional Resource Center University of North Carolina, MMRRC UNC, supported by the $\mathrm{NIH})$ mice. Cells were plated on Matrigel-coated coverslips in plating medium (MEM supplemented with $25 \mathrm{mM}$ glucose, $2.5 \mathrm{mM} \mathrm{NaHCO}_{3}, 100 \mu \mathrm{u} \mathrm{ml}^{-1}$ transferrin, $10 \%$ FCS, $2 \mathrm{mM}$ glutamine and $25 \mu \mathrm{g} \mathrm{ml}^{-1}$ insulin), and maintained at $37^{\circ} \mathrm{C}$ and $5 \% \mathrm{CO}_{2}$ in growth medium (Neurobasal-A medium supplemented with B27 (Gibco) and $2 \mathrm{mM}$ glutamine $)^{57}$. Transfection of superecliptic $\mathrm{SpH}$ and SytClopH was performed at 4 days in vitro (DIV) by a modified calcium phosphate transfection procedure ${ }^{56}$. Experiments were carried out at 15-25 DIV.

Recycling SV staining. In addition to $\mathrm{SpH}$ expression, SVs were labelled with FM1-43 (Invitrogen) and $\alpha$ VGAT-CypHer (Synaptic System). Neurons were exposed to $5 \mu \mathrm{M}$ FM1-43 during and for 5 min after stimulation (900 APs, $20 \mathrm{~Hz}$ ), and then washed thoroughly before imaging. To label SVs from GABAergic neurons, cells were incubated with $\alpha$ VGAT-CypHer in a $37^{\circ} \mathrm{C}$ incubator for $3-4 \mathrm{~h}$ in a carbonate buffer containing $105 \mathrm{mM} \mathrm{NaCl}, 20 \mathrm{mM} \mathrm{KCl}, 2.5 \mathrm{mM} \mathrm{CaCl}_{2}, 1 \mathrm{mM}$ $\mathrm{MgCl}_{2}, 10 \mathrm{mM}$ glucose, $18 \mathrm{mM} \mathrm{NaHCO}$. Cells were then washed three times before imaging.

Epifluorescence microscopy of living neurons. All experiments, unless otherwise stated, were carried out in $119 \mathrm{mM} \mathrm{NaCl}, 2.5 \mathrm{mM} \mathrm{KCl}, 2 \mathrm{mM} \mathrm{CaCl}, 2 \mathrm{mM} \mathrm{MgCl}_{2}$, $30 \mathrm{mM}$ glucose, $25 \mathrm{mM}$ HEPES pH 7.3. Neurons were stimulated by electric field stimulation (platinum electrodes, $10 \mathrm{~mm}$ spacing, $1 \mathrm{~ms}$ pulses of $50 \mathrm{~mA}$ and alternating polarity at $20 \mathrm{~Hz}$ ) applied by constant current stimulus isolator (WPI A 385, World Precision Instruments) in the presence of $10 \mu \mathrm{M} 6$-cyano-7-nitroquinoxaline-2,3-dione (CNQX) and $50 \mu \mathrm{M}$ D,L-2-amino-5-phosphonovaleric acid (AP5) to prevent recurrent activity. Fast solution exchanges were achieved through a three-barrel glass tubing perfusion system controlled by a piezo-controlled stepper device (SF778, Warner Instruments). In 'rapid acid quench' experiments the system was optimized for a fast and complete acid quench by adjusting the position of the glass pipette. Ammonium chloride solution ( $\mathrm{pH} 7.3$ ) was prepared by replacing $50 \mathrm{mM} \mathrm{NaCl}$ with $\mathrm{NH}_{4} \mathrm{Cl}$, while all other components remained unchanged. Acidic solution ( $\mathrm{pH}$ 5.25) was prepared by substituting HEPES with 45 $\mathrm{mM}$ 2-(N-morpholino)ethane sulphonic acid (MES). Chloride concentration was varied using different proportions of $\mathrm{NaCl}$ and sodium gluconate, sodium iodide or sodium methanesulfonate as stated while maintaining $\mathrm{Na}^{+}$concentration fixed at $119 \mathrm{mM}$. Chloride substitution is performed shortly before beginning of the measurement to minimize the effect on cytosolic anions. Rose Bengal (100 nM, 5 $\mathrm{min})$, Folimycin $(65 \mathrm{nM}, 1 \mathrm{~min})$ and Tetanus Neurotoxin (TeNT, $10 \mathrm{nM}, 16-18 \mathrm{~h}$ ) were added where indicated. Histidine $(10 \mathrm{mM})$ was added to buffers in all experiments were RB was involved. In experiment where $\mathrm{Ca}^{2+}$ is omitted, $\mathrm{Ca}^{2+}$ was replaced by an equimolar concentration of $\mathrm{Mg}^{2+}$ and $2 \mathrm{mM}$ EGTA was added.

Experiments were performed at room temperature on an inverted microscope (Axiovert S100TV, Zeiss) equipped with a $\times 63,1.2 \mathrm{NA}$ water-immersion objective. Images were acquired with a cooled CCD camera (Sensicam QE, PCO) controlled by TILLvisION software (TILL Photonics) in $2 \times 2$ binning mode resulting in $688 \times 520$ pixels. CypHer5E was excited at $640 \mathrm{~nm}$ and SpH or FM1-43 at $480 \mathrm{~nm}$ with a computer controlled monochromator (Polychrom II, Till Photonics). Fluorescence was detected after passing a FITC/Cy5 dual-band filter set (AHF Analysentechnik AG). Time lapse images were acquired at 0.5 or $5 \mathrm{~Hz}$ with integration times from 50 to $300 \mathrm{~ms}$. For dual-colour recordings alternating images in green and red channels were acquired.

Fig. 8 VGLUT activity slows SV acidification. a-c Rapid acid quench (Q) of surface SpH fluorescence following stimulation (S, $200 \mathrm{APs}$ at $20 \mathrm{~Hz})$ after $\mathrm{Cl}^{-}$ substitution with Gluc ${ }^{-}(\mathbf{a})$ or $\mathrm{MeS}^{-}(\mathbf{b})$ with or without RB (100 nM, $\left.5 \mathrm{~min}\right)(n=8-17)$ and in wild-type or VGLUT1-deficient boutons (c) ( $n=41$ for wild

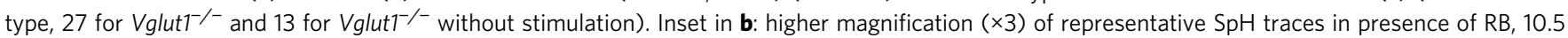
$\mathrm{mM} \mathrm{Cl}^{-}$and $119 \mathrm{mM} \mathrm{MeS}^{-}$with normal ( $25 \mathrm{mM}$, red, $n=8$ ) or low ( $5 \mathrm{mM}$, blue, $\left.n=14\right)$ HEPES concentration, compared to the fluorescence intensity change due to acidic buffer only (grey). Right panels: higher magnification of the acidification kinetics during the acid quench, fitted with single exponentials. Traces in a-c represent responses of glutamatergic boutons only. $\mathbf{d}$ Fluorescent images of SpH-transfected neurons from panel $\mathbf{c}$ at various time after the onset of stimulation. Scale bars represent $2 \mu \mathrm{m}$. e Bar graph of acidification time constants in different conditions presented in a-c. ${ }^{\star \star \star} P<$

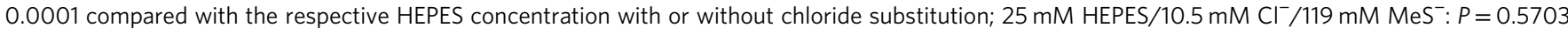
compared with $5 \mathrm{mM} \mathrm{HEPES/10.5} \mathrm{mM} \mathrm{Cl}^{-} / 119 \mathrm{mM} \mathrm{Gluc}^{-}$; $25 \mathrm{mM} \mathrm{HEPES} / 10.5 \mathrm{mM} \mathrm{Cl}^{-} / 119 \mathrm{mM} \mathrm{MeS}-/ \mathrm{RB}$ : $P=0.1825$ compared with $5 \mathrm{mM} \mathrm{HEPES/10.5}$ $\mathrm{mM} \mathrm{Cl}^{-} / 119 \mathrm{mM} \mathrm{Gluc}{ }^{-} / \mathrm{RB}$; analysed with two-tailed unpaired $t$-test. Sketches in a-c and $\mathbf{e}$ illustrate $\mathrm{H}^{+}$movements. Dark grey and light grey circles symbolize V-ATPase and VGLUT, respectively. $\mathrm{Cl}^{-}$-filled SVs are represented by grey-filled circles and $\mathrm{Gluc}^{-}$or $\mathrm{Mes}^{-}$-filled $\mathrm{SV}$ by open circles. n.s. non significant; ${ }^{* \star \star}$ significant changes; ${ }^{\#}$ the time constants for $5 \mathrm{mM} \mathrm{HEPES}, \mathrm{MeS}^{-}, \mathrm{RB}$ (inset in b), and for Vglut ${ }^{-/-}$(c) are overestimated due to traces with an acidification too fast to be separated from the acid quench and fitted (3/14 and $9 / 27$ traces, respectively). Error bars represent s.e.m. They are shown every tenth point $(2 \mathrm{~s})$ for better visibility 

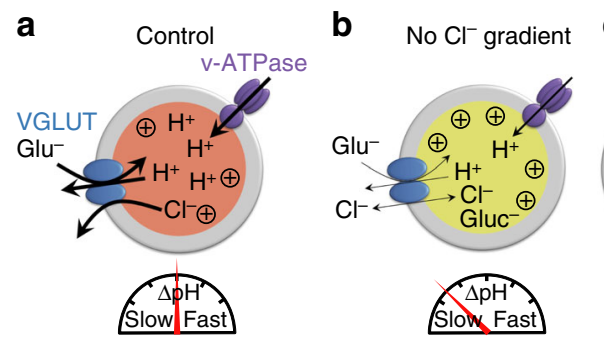

C VGLUT1 KO

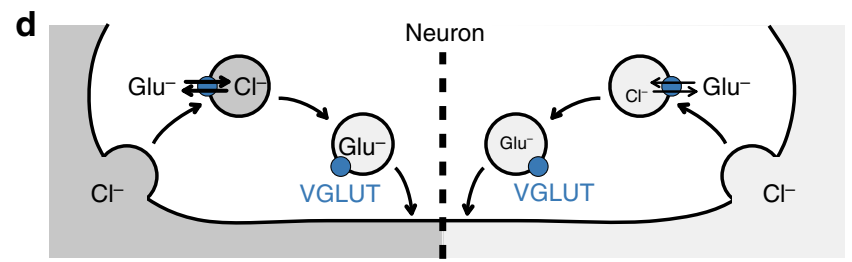

Fig. 9 Model for VGLUT transport mechanism and SV re-acidification. Luminal $\mathrm{pH}$ is indicated by the green-red scale. Re-acidification rates are represented by a speedometer. Strength of $\Delta \Psi$ is symbolized by $(+)$. a In presence of high luminal $\mathrm{Cl}^{-}$, efflux of $\mathrm{Cl}^{-}$facilitates glutamate uptake by generating $\Delta \Psi$. The glutamate $/ \mathrm{Cl}^{-}$exchange mechanism allows an electroneutral SV filling without increasing the osmotic pressure. As the luminal $\mathrm{Cl}^{-}$concentration gradually decreases, glutamate uptake is driven by the $\Delta \Psi$ generated by the $V$-ATPase. Glutamate transport finally stops when $\Delta \Psi$ vanishes and luminal $\mathrm{pH}$ decreases. $\mathbf{b}$ In absence of a permeant anion in the vesicular lumen (e.g. Gluc ${ }^{-}$or $\mathrm{MeS}^{-}$), glutamate uptake is fuelled solely by the V-ATPase and is limited by the osmolarity. The overall process of loading and acidification is slow. Additionally, if $\mathrm{Gluc}^{-}$is used as a substitute for $\mathrm{Cl}^{-}$, its buffering capacity prevents luminal acidification in presence of high HEPES concentrations. $\mathbf{c}$ In absence of VGLUT, acidification is strongly accelerated. $\mathrm{KO}$ knockout, $\mathrm{Glu}^{-}$glutamate, $\mathrm{Gluc}^{-}$ gluconate, $\mathrm{MeS}^{-}$methanesulfonate. d Illustration of glutamate loading at synaptic terminal during recycling of SV. During endocytosis, $\mathrm{Cl}^{-}$is engulfed inside SV from the extracellular space. The anion is subsequently exchange for glutamate through VGLUT. Left: high $\mathrm{Cl}^{-}$concentration, right: low $\mathrm{Cl}^{-}$concentration

Functional analysis of VGLUT in HEK293T cells. For electrophysiological analysis of VGLUT anion currents in mammalian cells, we subcloned rat VGLUT1 cDNAs (kindly provided by Dr. Shigeo Takamori) into pcDNA3.1 and mutated the dileucine-like endocytosis motif to alanine as reported by Eriksen et al. ${ }^{17}$. HEK 293 cells passage 3-5 (cell line name; tsA201, Cat. No. 96121229, Sigma-Aldrich) were transiently transfected with $2-5 \mu \mathrm{g}$ of plasmid DNA using a calcium phosphate precipitation method and examined $36 \mathrm{~h}$ later. In brief, DNA was mixed with 330 $\mu \mathrm{l}$ of buffered water (2.5 mM HEPES) and $56.5 \mu \mathrm{l}$ of $2.5 \mathrm{M} \mathrm{CaCl}_{2}$ by pipetting, subsequently $570 \mu \mathrm{l}$ of $2 \times \mathrm{HeBS}$ buffer $(280 \mathrm{nM} \mathrm{NaCl}, 50 \mathrm{mM}$ HEPES, $1.5 \mathrm{mM}$ $\mathrm{Na}_{2} \mathrm{PO}_{4}$, adjusted with $2 \mathrm{M} \mathrm{NaOH}$ to $\mathrm{pH} 7.00$ ) was added dropwise under agitation by vortexing. The DNA-Calcium precipitate was leaved at room temperature for 5 min and thereafter was added to the HEK 293 cells (cultured in a $5 \mathrm{~cm}$ dish with 70-80\% confluence).

Standard whole-cell patch clamp recordings were performed using an EPC-10 amplifier, controlled by PatchMaster (HEKA, Germany) ${ }^{58}$. Borosilicate pipettes (Harvard Apparatus, USA) were pulled with resistances of $0.9-2 \mathrm{M} \Omega$. Series resistance compensation and capacitance cancellation were applied, resulting in $<5$ $\mathrm{mV}$ voltage error. The standard external solutions contained (in $\mathrm{mM}$ ) 145 Choline $\mathrm{Cl}, 50$ MES (2-( $N$-morpholino)ethanesulfonate) $2 \mathrm{Mg}$-Gluconate, $\mathrm{pH}$ 5.0, with and without RB $(10 \mathrm{nM})$. Cells were dialysed with an internal solution containing 10 $\mathrm{NaCl}, 30$ HEPES, 100 TMA Gluconate, $2 \mathrm{MgCl}_{2}, 5$ EGTA; $\mathrm{pH}$ 7.4, and held at -85 $\mathrm{mV}$ to established a physiologically low cytoplasmic $\left[\mathrm{Cl}^{-}\right]$. The junction potential was calculated and corrected.

Imaging vesicular $\mathrm{Cl}^{-}$in living neurons. For vesicular $\mathrm{Cl}^{-}$imaging SytClopH was used as a ratiometric indicator by excitation. Imaging was performed at room temperature on an inverted microscope (Axiovert 100TV, Zeiss) equipped with a $\times 63,1.2 \mathrm{NA}$ water-immersion objective. Images were acquired with a sCMOS camera (Neo 5.5, Andor) controlled by Andor IQ software (Andor) in $2 \times 2$ binning mode. SytClopH was excited sequentially at 458,488 and $565 \mathrm{~nm}$ with a computer controlled monochromator (Polychrom V, Till Photonics). Emission was collected with a 525/50 nm Brightline single-band bandpass emission filter when excited at 458 and $488 \mathrm{~nm}$, and with a 609/54 nm Brightline single-band bandpass emission filter when excited at $565 \mathrm{~nm}$. Calibration of SytClopH was performed on hippocampal cultured neurons ${ }^{37}$ using Image J software (US National Institutes of Health) as follows. Intracellular $\mathrm{pH}$ and $\mathrm{Cl}^{-}$were controlled by equilibrating extraand intracellular ion concentrations for at least $15 \mathrm{~min}$ using the $\mathrm{K}^{+} / \mathrm{H}^{+}$exchanger nigericin $(10 \mu \mathrm{M})$ and the $\mathrm{Cl}^{-} / \mathrm{OH}^{-}$exchanger tributyltinchloride $(10 \mu \mathrm{M})$ in a high $\mathrm{K}^{+}$containing buffer of different $\left[\mathrm{Cl}^{-}\right]$. The buffers of different $\left[\mathrm{Cl}^{-}\right]$were prepared by mixing two solutions containing 4 or $131 \mathrm{mM} \mathrm{Cl}^{-}$. The $4 \mathrm{mM} \mathrm{Cl}^{-}$solution was composed of $123 \mathrm{mM}$ K gluconate, $2 \mathrm{mM} \mathrm{CaCl}, 2 \mathrm{mM} \mathrm{MgSO}_{4}, 1.2 \mathrm{mM} \mathrm{NaH}_{2} \mathrm{PO}_{4}$, $11 \mathrm{mM}$ glucose, $23 \mathrm{mM}$ HEPES. The $131 \mathrm{mM} \mathrm{Cl}^{-}$solution contained $123 \mathrm{mM} \mathrm{KCl}$, $2 \mathrm{mM} \mathrm{CaCl} 2,2 \mathrm{mM} \mathrm{MgCl}_{2}, 1.2 \mathrm{mM} \mathrm{NaH}_{2} \mathrm{PO}_{4}, 11 \mathrm{mM}$ glucose, $23 \mathrm{mM}$ HEPES. $\mathrm{pH}$ was adjusted with $\mathrm{NaOH}$. The calibrated buffers allowed the measurement of $R_{\mathrm{pH}}$ $\left(F_{488 \mathrm{~nm}} / F_{458 \mathrm{~nm}}\right)$ and $R_{\mathrm{Cl}}\left(F_{458 \mathrm{~nm}} / F_{565 \mathrm{~nm}}\right)$ at different known $\left[\mathrm{Cl}^{-}\right]$and $\mathrm{pH}$. For all experimental data, $\mathrm{pH}$ and $\left[\mathrm{Cl}^{-}\right]$were determined by the following equations ${ }^{37}$ :

$$
\begin{gathered}
\mathrm{pH}=\mathrm{p} K_{\mathrm{a}}+\log \left(\frac{R_{\mathrm{pH}}-R_{\mathrm{A}}}{R_{\mathrm{B}}-R_{\mathrm{pH}}}\right), \\
{\left[\mathrm{Cl}^{-}\right]=K_{\mathrm{d}}^{\mathrm{Cl}}\left(\frac{R_{\mathrm{Cl}}-R_{\text {free }}}{R_{\text {bound }}-R_{\mathrm{Cl}}}\right),}
\end{gathered}
$$

$\mathrm{p} K_{\mathrm{a}}$ is the acid dissociation constant of SytClopH. $R_{\mathrm{A}}$ and $R_{\mathrm{B}}$ are the values of $R_{\mathrm{pH}}$ for the sensor in its most acidic and basic forms. $R_{\text {free }}$ is the maximum value of $R_{\mathrm{Cl}}$ when no $\mathrm{Cl}^{-}$is bound to SytClopH. $R_{\mathrm{bound}}$ is the maximum value of $R_{\mathrm{Cl}}$ when SytClopH is saturated with $\mathrm{Cl}^{-}$. $R_{\text {bound }}$ is proportional to $\mathrm{pH}$ with slope $M$, which we determined empirically to be $0.061 \mathrm{per} \mathrm{pH}$ unit:

$$
R_{\text {bound }}=M(\mathrm{pH})+R_{\text {bound, } \mathrm{pH} 0},
$$

$K_{\mathrm{d}}^{\mathrm{Cl}}$ is the $\mathrm{Cl}^{-}$dissociation constant which depends on $\mathrm{pH}$ :

$$
K_{\mathrm{d}}^{\mathrm{Cl}}={ }^{1} K_{\mathrm{d}}^{\mathrm{Cl}}\left(\frac{1+10^{(\mathrm{pKa}-\mathrm{pH})}}{10^{(\mathrm{pKa}-\mathrm{pH})}}\right)
$$

${ }^{1} K_{\mathrm{d}}^{\mathrm{Cl}}$ reflects the $\mathrm{Cl}^{-}$dissociation constant when SytClopH is fully protonated.

Proteolytic cleavage of ClopHensorN from the plasma membrane was performed at room temperature by adding $60 \mathrm{U} \mathrm{ml}^{-1}$ AcTEV protease (SigmaAldrich) and $1 \mathrm{mM}$ dithiothreitol directly to the living neurons for $15 \mathrm{~min}^{56}$. After digestion, cells were washed for $5 \mathrm{~min}$.

Data analysis. Fluorescence time series data were analysed with an automated algorithm for bouton detection in order to avoid experimenter bias using selfwritten macros in Igor Pro (Wavemetrics). For detecting regions of fluorescence intensity changes (functional boutons) the difference image of the images before and at the end of stimulation (maximum change in fluorescence intensity) of a time series was subjected to an à trous wavelet transform with the level $k=4$ and detection level $l_{\mathrm{d}}=1.0^{56}$. The result is a binary mask showing spots (synaptic boutons) of fluorescence intensity changes that is used to extract individual fluorescence time series of all synaptic boutons in the field of view. For experiments involving VGLUT1 knockout mice we excluded the responses from boutons containing another VGLUT isoform by applying RB at the end of the experiment and sorting the inhibited boutons ( 725 boutons over a total of 2388 ; i.e. $30 \%$, in line with a previous study ${ }^{6}$ ). These VGLUT-positive boutons showed a time constant for acidification similar to boutons from wild-type mice (Supplementary Fig. 9). Only experiments containing $>50$ active boutons were considered for analysis. All data are represented as mean \pm s.e.m. of $n$ experiments. In 'rapid acid quench' experiments, s.e.m. are shown every tenth point $(2 \mathrm{~s})$ for better visibility. Acidification time courses were fitted to mono-exponential decay functions using Igor Pro. All statistical tests performed were two-tailed unpaired $t$-tests.

Estimation of the vesicular $\mathbf{p H}$. The total fluorescence of $\mathrm{SpH}$ in a terminal is the sum of the fluorescence derived from different $\mathrm{SpH}$ fractions, including those on the cell surface, those within resting SVs, and those within recycling SVs. We can estimate that only the recycling SVs contribute to the change in fluorescence monitored after the end of the stimulation. Therefore, the fluorescence intensities at each $\mathrm{pH}$ can be described by the Henderson-Hasselbalch equation as follows:

$$
\begin{array}{r}
\Delta F=\left(F-F_{0}\right) / F_{\max }=\left(1 /\left(1+10^{\mathrm{nH}(\mathrm{p} K \mathrm{a}-\mathrm{pH})}\right)\right. \\
\left.-1 /\left(1+10^{\mathrm{nH}(\mathrm{p} K \mathrm{a}-5.6)}\right)\right)\left(1+10^{\mathrm{nH}(\mathrm{p} K \mathrm{a}-7.3)}\right),
\end{array}
$$

where $F_{0}$ is the fluorescence at rest so at a luminal $\mathrm{pH}$ of 5.6, $F_{\max }$ is the fluorescence at the surface, at $\mathrm{pH} 7.3, \mathrm{pKa}$ is the $\mathrm{pH}$ at which $50 \%$ of the probe is protonated and $\mathrm{nH}$ is the Hill coefficient. Upon normalization of the $\mathrm{SpH}$ traces between the baseline at rest and the climax of stimulation, $F_{0}=0$ and $F_{\max }=1$. For pHluorin, the $\mathrm{pKa}$ and $\mathrm{nH}$ values are 7.09 and 1.35 , respectively ${ }^{47}$. From this equation, we can determine the averaged $\mathrm{pH}$ of the recycling probes at each 
fluorescence intensity $\Delta F$ following:

$\mathrm{pH}=\mathrm{pKa}-1 / \mathrm{nH} \log \left[1 /\left(1 /\left(1+10^{\mathrm{nH}(\mathrm{pKa}-5.6)}\right)+\Delta F /\left(1+10^{\mathrm{nH}(\mathrm{pKa}-7.3)}\right)\right)-1\right]$.

The $\mathrm{SpH}$ fluorescence decay after stimulation was fitted by a single exponential decay and the vesicular $\mathrm{pH}$ reached at steady state is calculated depending on the $\Delta F$ reached at the plateau.

Data availability. Data supporting the findings of this manuscript are available from the corresponding authors upon reasonable request.

Received: 31 October 2016 Accepted: 24 November 2017

Published online: 22 December 2017

\section{References}

1. Edwards, R. H. The neurotransmitter cycle and quantal size. Neuron 55, 835-858 (2007)

2. Saheki, Y. \& De Camilli, P. Synaptic vesicle endocytosis. Cold Spring Harb. Perspect. Biol. 4 a005645 (2012).

3. Omote, H., Miyaji, T., Juge, N. \& Moriyama, Y. Vesicular neurotransmitter transporter: bioenergetics and regulation of glutamate transport. Biochemistry 50, 5558-5565 (2011)

4. He, H. et al. Neurodevelopmental role for VGLUT2 in pyramidal neuron plasticity, dendritic refinement, and in spatial learning. J. Neurosci. 32, 15886-15901 (2012).

5. Moechars, D. et al. Vesicular glutamate transporter VGLUT2 expression levels control quantal size and neuropathic pain. J. Neurosci. 26, 12055-12066 (2006).

6. Wojcik, S. M. et al. An essential role for vesicular glutamate transporter 1 (VGLUT1) in postnatal development and control of quantal size. Proc. Natl Acad. Sci. USA 101, 7158-7163 (2004).

7. Eastwood, S. L. \& Harrison, P. J. Decreased expression of vesicular glutamate transporter 1 and complexin II mRNAs in schizophrenia: further evidence for a synaptic pathology affecting glutamate neurons. Schizophr. Res. 73, 159-172 (2005).

8. Oni-Orisan, A., Kristiansen, L. V., Haroutunian, V., Meador-Woodruff, J. H. \& McCullumsmith, R. E. Altered vesicular glutamate transporter expression in the anterior cingulate cortex in schizophrenia. Biol. Psychiatry 63, 766-775 (2008).

9. Kashani, A. et al. Loss of VGLUT1 and VGLUT2 in the prefrontal cortex is correlated with cognitive decline in Alzheimer disease. Neurobiol. Aging 29, 1619-1630 (2008).

10. Favier, M. et al. High-frequency stimulation of the subthalamic nucleus modifies the expression of vesicular glutamate transporters in basal ganglia in a rat model of Parkinson's disease. BMC Neurosci. 14, 1471-2202 (2013).

11. Kashani, A., Betancur, C., Giros, B., Hirsch, E. \& El Mestikawy, S. Altered expression of vesicular glutamate transporters VGLUT1 and VGLUT2 in Parkinson disease. Neurobiol. Aging 28, 568-578 (2007).

12. Juge, N. et al. Metabolic control of vesicular glutamate transport and release. Neuron 68, 99-112 (2010)

13. van der Hel, W. S. et al. Hippocampal distribution of vesicular glutamate transporter 1 in patients with temporal lobe epilepsy. Epilepsia 50, 1717-1728 (2009).

14. Ni, B., Rosteck, P. R. Jr, Nadi, N. S. \& Paul, S. M. Cloning and expression of a cDNA encoding a brain-specific $\mathrm{Na}(+)$-dependent inorganic phosphate cotransporter. Proc. Natl Acad. Sci. USA 91, 5607-5611 (1994).

15. Bellocchio, E. E., Reimer, R. J., Fremeau, R. T. Jr. \& Edwards, R. H. Uptake of glutamate into synaptic vesicles by an inorganic phosphate transporter. Science 289, 957-960 (2000).

16. Takamori, S., Rhee, J. S., Rosenmund, C. \& Jahn, R. Identification of a vesicular glutamate transporter that defines a glutamatergic phenotype in neurons. Nature 407, 189-194 (2000).

17. Eriksen, J. et al. Protons regulate vesicular glutamate transporters through an allosteric mechanism. Neuron 90, 1-13 (2016).

18. Maycox, P. R., Deckwerth, T., Hell, J. W. \& Jahn, R. Glutamate uptake by brain synaptic vesicles. Energy dependence of transport and functional reconstitution in proteoliposomes. J. Biol. Chem. 263, 15423-15428 (1988).

19. Wolosker, H., de Souza, D. O. \& de Meis, L. Regulation of glutamate transport into synaptic vesicles by chloride and proton gradient. J. Biol. Chem. 271, 11726-11731 (1996)

20. Juge, N., Yoshida, Y., Yatsushiro, S., Omote, H. \& Moriyama, Y. Vesicular glutamate transporter contains two independent transport machineries. J. Biol. Chem. 281, 39499-39506 (2006).

21. Winter, S. et al. Galphao2 regulates vesicular glutamate transporter activity by changing its chloride dependence. J. Neurosci. 25, 4672-4680 (2005).
22. Farsi, Z. et al. Single-vesicle imaging reveals different transport mechanisms between glutamatergic and GABAergic vesicles. Science 351, 981-984 (2016).

23. Schenck, S., Wojcik, S. M., Brose, N. \& Takamori, S. A chloride conductance in VGLUT1 underlies maximal glutamate loading into synaptic vesicles. Nat. Neurosci. 12, 156-162 (2009).

24. Preobraschenski, J., Zander, J. F., Suzuki, T., Ahnert-Hilger, G. \& Jahn, R. Vesicular glutamate transporters use flexible anion and cation binding sites for efficient accumulation of neurotransmitter. Neuron 84, 1287-1301 (2014).

25. Roseth, S., Fykse, E. M. \& Fonnum, F. Uptake of L-glutamate into rat brain synaptic vesicles: effect of inhibitors that bind specifically to the glutamate transporter. J. Neurochem. 65, 96-103 (1995).

26. Ogita, K. et al. Inhibition of vesicular glutamate storage and exocytotic release by Rose Bengal. J. Neurochem. 77, 34-42 (2001).

27. Wilson, N. R. et al. Presynaptic regulation of quantal size by the vesicular glutamate transporter VGLUT1. J. Neurosci. 25, 6221-6234 (2005).

28. Valencia, A. \& Moran, J. Reactive oxygen species induce different cell death mechanisms in cultured neurons. Free Radic. Biol. Med. 36, 1112-1125 (2004).

29. Hua, Y. et al. A readily retrievable pool of synaptic vesicles. Nat. Neurosci. 14, 833-839 (2011).

30. Zhang, Z., Nguyen, K. T., Barrett, E. F. \& David, G. Vesicular ATPase inserted into the plasma membrane of motor terminals by exocytosis alkalinizes cytosolic pH and facilitates endocytosis. Neuron 68, 1097-1108 (2010).

31. Kuner, T. \& Augustine, G. J. A genetically encoded ratiometric indicator for chloride: capturing chloride transients in cultured hippocampal neurons. Neuron 27, 447-459 (2000).

32. Markova, O., Mukhtarov, M., Real, E., Jacob, Y. \& Bregestovski, P. Genetically encoded chloride indicator with improved sensitivity. J. Neurosci. Methods 170, 67-76 (2008)

33. Duran, C., Thompson, C. H., Xiao, Q. \& Hartzell, H. C. Chloride channels: often enigmatic, rarely predictable. Annu. Rev. Physiol. 72, 95-121 (2010).

34. Wadiche, J. I. \& Kavanaugh, M. P. Macroscopic and microscopic properties of a cloned glutamate transporter/chloride channel. J. Neurosci. 18, 7650-7661 (1998).

35. Juge, N., Muroyama, A., Hiasa, M., Omote, H. \& Moriyama, Y. Vesicular inhibitory amino acid transporter is a $\mathrm{Cl}$-/gamma-aminobutyrate cotransporter. J. Biol. Chem. 284, 35073-35078 (2009).

36. Machtens, J. P. et al. Mechanisms of anion conduction by coupled glutamate transporters. Cell 160, 542-553 (2015).

37. Raimondo, J. V. et al. A genetically-encoded chloride and $\mathrm{pH}$ sensor for dissociating ion dynamics in the nervous system. Front. Cell. Neurosci. 7, 202 (2013).

38. Atluri, P. P. \& Ryan, T. A. The kinetics of synaptic vesicle reacidification at hippocampal nerve terminals. J. Neurosci. 26, 2313-2320 (2006).

39. Farsi, Z., Jahn, R. \& Woehler, A. Proton electrochemical gradient: driving and regulating neurotransmitter uptake. Bioessays 39, 1600240 (2017).

40. Takamori, S. et al. Molecular anatomy of a trafficking organelle. Cell 127 831-846 (2006)

41. Groemer, T. W. \& Klingauf, J. Synaptic vesicles recycling spontaneously and during activity belong to the same vesicle pool. Nat. Neurosci. 10, 145-147 (2007).

42. Zhou, Q., Petersen, C. C. \& Nicoll, R. A. Effects of reduced vesicular filling on synaptic transmission in rat hippocampal neurones. J. Physiol. 525.1, 195-206 (2000).

43. Sankaranarayanan, S., De Angelis, D., Rothman, J. E. \& Ryan, T. A. The use of pHluorins for optical measurements of presynaptic activity. Biophys. J. 79, 2199-2208 (2000).

44. Balaji, J. \& Ryan, T. A. Single-vesicle imaging reveals that synaptic vesicle exocytosis and endocytosis are coupled by a single stochastic mode. Proc. Natl Acad. Sci. USA 104, 20576-20581 (2007).

45. Sinha, R., Ahmed, S., Jahn, R. \& Klingauf, J. Two synaptobrevin molecules are sufficient for vesicle fusion in central nervous system synapses. Proc. Natl Acad. Sci. USA 108, 14318-14323 (2011).

46. Minagawa, Y. et al. Basic properties of rotary dynamics of the molecular motor Enterococcus hirae V1-ATPase. J. Biol. Chem. 288, 32700-32707 (2013).

47. Egashira, Y., Takase, M. \& Takamori, S. Monitoring of vacuolar-type $H$ +ATPase-mediated proton influx into synaptic vesicles. J. Neurosci. 35, 3701-3710 (2015).

48. Klyachko, V. A. \& Jackson, M. B. Capacitance steps and fusion pores of small and large-dense-core vesicles in nerve terminals. Nature 418, 89-92 (2002).

49. Neher, E. \& Marty, A. Discrete changes of cell membrane capacitance observed under conditions of enhanced secretion in bovine adrenal chromaffin cells. Proc. Natl Acad. Sci. USA 79, 6712-6716 (1982).

50. Jentsch, T. J., Neagoe, I. \& Scheel, O. CLC chloride channels and transporters. Curr. Opin. Neurobiol. 15, 319-325 (2005).

51. Guzman, R. E., Alekov, A. K., Filippov, M., Hegermann, J. \& Fahlke, C. Involvement of ClC-3 chloride/proton exchangers in controlling glutamatergic synaptic strength in cultured hippocampal neurons. Front. Cell. Neurosci. 8, 143 (2014). 
52. Stobrawa, S. M. et al. Disruption of ClC-3, a chloride channel expressed on synaptic vesicles, leads to a loss of the hippocampus. Neuron 29, 185-196 (2001).

53. Daniels, R. W. et al. A single vesicular glutamate transporter is sufficient to fill a synaptic vesicle. Neuron 49, 11-16 (2006).

54. Poëa-Guyon, S. et al. The V-ATPase membrane domain is a sensor of granular pH that controls the exocytotic machinery. J. Cell Biol. 203, 283-298 (2013).

55. Herman, M. A., Ackermann, F., Trimbuch, T. \& Rosenmund, C. Vesicular glutamate transporter expression level affects synaptic vesicle release probability at hippocampal synapses in culture. J. Neurosci. 34, 11781-11791 (2014).

56. Wienisch, M. \& Klingauf, J. Vesicular proteins exocytosed and subsequently retrieved by compensatory endocytosis are nonidentical. Nat. Neurosci. 9, 1019-1027 (2006).

57. Hua, Y. et al. Blocking endocytosis enhances short-term synaptic depression under conditions of normal availability of vesicles. Neuron 80, 343-349 (2013).

58. Guzman, R. E., Grieschat, M., Fahlke, C. \& Alekov, A. K. ClC-3 is an intracellular chloride/proton exchanger with large voltage-dependent nonlinear capacitance. ACS Chem. Neurosci. 4, 994-1003 (2013).

\section{Acknowledgements}

The authors are grateful to K. Tkotz for expert technical assistance and M. Kahms for advices in imaging and valuable discussions. M.M. was the recipient of a Marie Curie Intra-European Fellowship for Career Development (IEF) under the 7th Framework Program (FP7) of the European Commission. J.K. was supported by grants from the DFG (SFB 629, SFB 944 and DFG EXC 1003, Cells in Motion Cluster of Excellence, Münster, Germany) and by a grant of the IZKF Münster (Project No. Kli3/027/15).

\section{Author contributions}

M.M. and J.K. designed the project and wrote the manuscript, M.M. performed experiments on cultured neurons and with J.K. analysed the data, R.E.G. and C.F. planned, performed and analysed experiments on transfected HEK293T cells and provided the Vglut1 $^{-/-}$mice.

\section{Additional information}

Supplementary Information accompanies this paper at https://doi.org/10.1038/s41467 017-02367-6.

Competing interests: The authors declare no competing financial interests.

Reprints and permission information is available online at http://npg.nature.com/ reprintsandpermissions/

Publisher's note: Springer Nature remains neutral with regard to jurisdictional claims in published maps and institutional affiliations.

\begin{abstract}
(c) (i) Open Access This article is licensed under a Creative Commons Attribution 4.0 International License, which permits use, sharing, adaptation, distribution and reproduction in any medium or format, as long as you give appropriate credit to the original author(s) and the source, provide a link to the Creative Commons license, and indicate if changes were made. The images or other third party material in this article are included in the article's Creative Commons license, unless indicated otherwise in a credit line to the material. If material is not included in the article's Creative Commons license and your intended use is not permitted by statutory regulation or exceeds the permitted use, you will need to obtain permission directly from the copyright holder. To view a copy of this license, visit http://creativecommons.org/ licenses/by/4.0/.
\end{abstract}

(C) The Author(s) 2017 